\title{
WestVirginiaUniversity
}

THE RESEARCH REPOSITORY @ WVU

Graduate Theses, Dissertations, and Problem Reports

2019

\section{Conceptual Design of MALE UAVs}

Vincent Spada

Vincent Spada, vspada@mix.wvu.edu

Follow this and additional works at: https://researchrepository.wvu.edu/etd

Part of the Other Aerospace Engineering Commons

\section{Recommended Citation}

Spada, Vincent, "Conceptual Design of MALE UAVs" (2019). Graduate Theses, Dissertations, and Problem Reports. 7374.

https://researchrepository.wvu.edu/etd/7374

This Problem/Project Report is protected by copyright and/or related rights. It has been brought to you by the The Research Repository @WVU with permission from the rights-holder(s). You are free to use this Problem/Project Report in any way that is permitted by the copyright and related rights legislation that applies to your use. For other uses you must obtain permission from the rights-holder(s) directly, unless additional rights are indicated by a Creative Commons license in the record and/ or on the work itself. This Problem/Project Report has been accepted for inclusion in WVU Graduate Theses, Dissertations, and Problem Reports collection by an authorized administrator of The Research Repository @ WVU. For more information, please contact researchrepository@mail.wvu.edu. 


\section{Conceptual Design of MALE UAVs}

Vincent P. Spada Jr.

Problem Report submitted

to The Statler College of Engineering and Mineral Resources at West Virginia University

in partial fulfillment of the requirements for the degree of

Master of Science in

Aerospace Engineering

Peter D. Gall, Ph.D., Chair

Patrick Browning, Ph.D.

Wade W. Huebsch, Ph.D.

Department of Mechanical and Aerospace Engineering

Morgantown, West Virginia

2019

Keywords: Conceptual Design, Unmanned Aerial Vehicles, Supercomputer

Copyright 2019 Vincent Spada 


\section{ABSTRACT \\ Conceptual Design of MALE UAVs}

Vincent P. Spada Jr.

The conceptual design process of aircraft involves the creation of a product, in this case UAVS (unmanned aerial vehicles), using the most effective means possible across multiple subdisciplines of Aerospace Engineering. This paper will outline a unique methodology that involves calculating certain design variables such as wing loading, power loading, aspect ratio and cruise altitude in the conceptual design phase for MALE (medium altitude long endurance) UAVs. Aircraft characteristics from MALE UAVs such as the MQ-9 predator and MQ-1 reaper will used for a comparative aircraft study as "jumping off" points in order to carry out the initial calculations.

An intensive computational computer program was created to perform the appropriate calculations in an iterative process. These calculations, details outlined in this paper, involved the usage of both empirical and analytical weight equations, to calculate the $s$ (structural factor), and series of aerodynamic equations, to calculate the $L / D_{c r s}$ (Lift over Drag at cruise) which are both the termination criteria. The iterative process mainly involves cycling through numerous aspect ratios, wing loadings and cruise altitudes to generate a family of aircraft that can be plotted against lines of constant TOGW (take-off gross weight) and design constraint such as Landing and Takeoff distances. The most efficient design can then be derived within the bounds of the design constraints at the lowest $T O G W$.

Due to the intensive computational nature of the analytical method for calculating the weight of the wing, a cluster computer made up of a series of Raspberry PIs was developed to ease the computational time.

This unique design process was able to successfully allow the user to generate a MALE UAV within certain design constraints per user request. 


\section{Acknowledgments}

I would like to first acknowledge my advisor and mentor Dr. Peter Gall. Dr. Gall has guided me throughout both my undergraduate and graduate studies at WVU. I contribute my current status as an Aerospace Engineer to his unconditional support. I would also like to thank my family for all their love and support. 


\section{Table of Contents}

List of Tables …

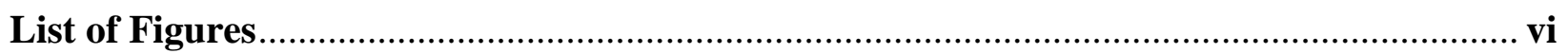

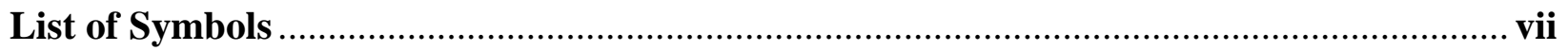

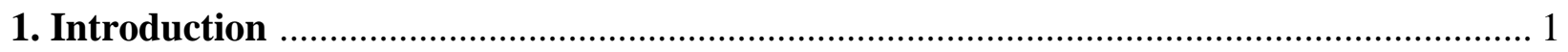

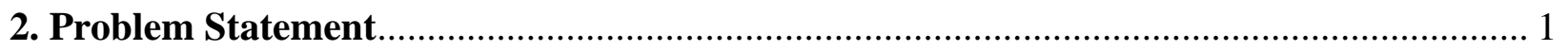

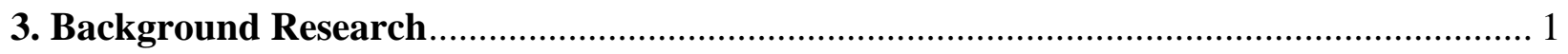

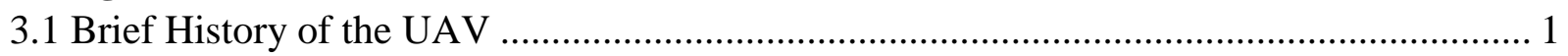

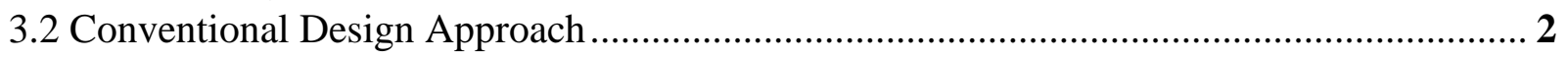

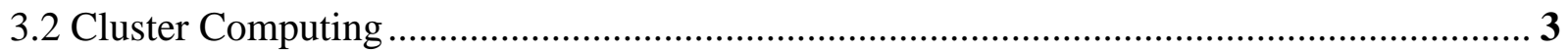

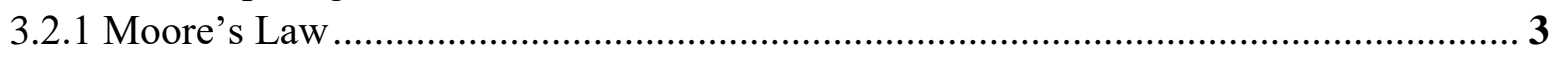

3.2.2 Aircraft Design and Supercomputers ..................................................................... 4

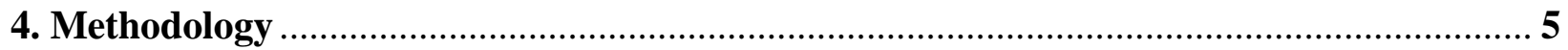

4.1 Process of Conceptual Design ....................................................................................... 5

4.2 Preliminary Calculations of Parameters............................................................................. 7

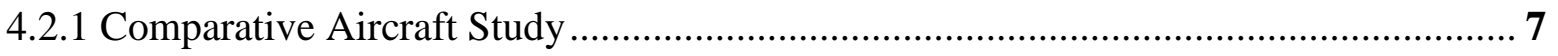

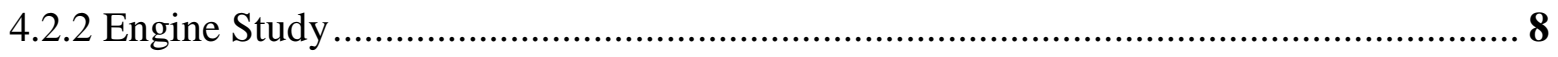

4.2.3 Initialization of Takeoff Gross Weight .......................................................................... 9

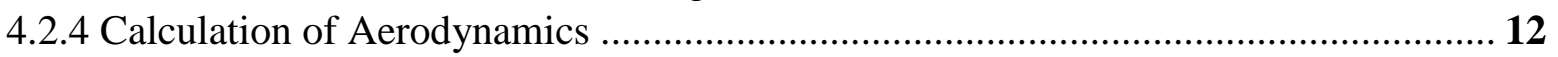

4.2.5 Calculation of Weights .................................................................................... 14

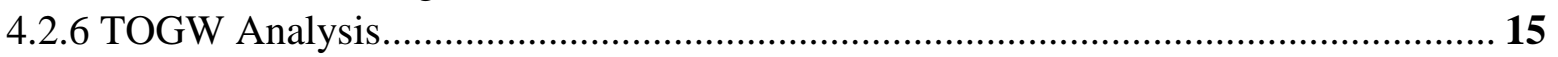

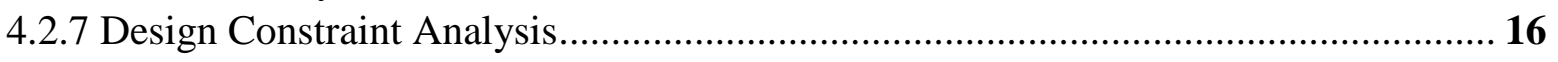

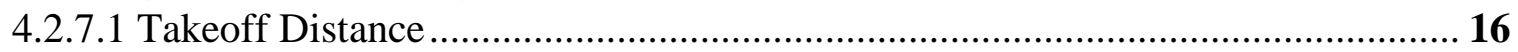

4.2.7.2 Landing Distance ………………………………......................................... 20

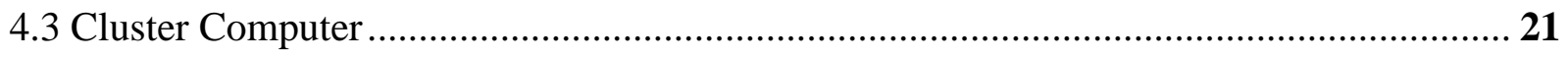

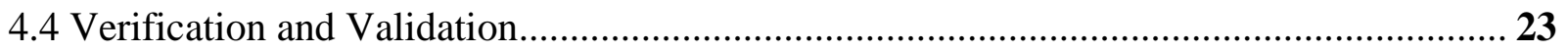

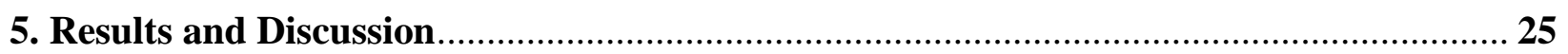

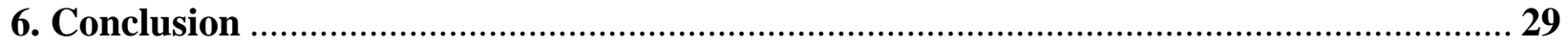

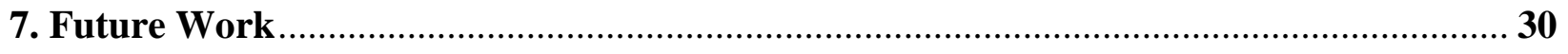

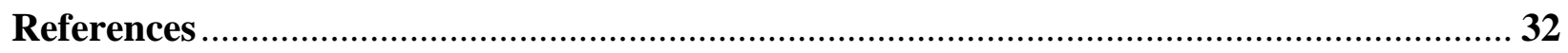

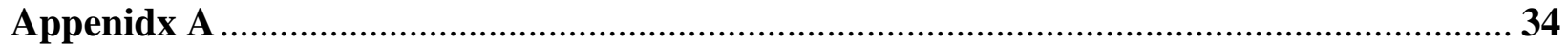

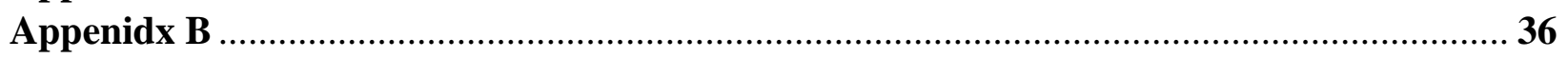

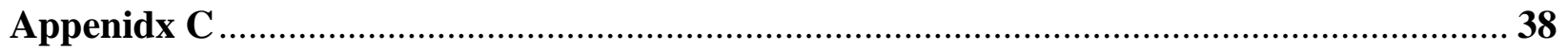




\section{List of Tables}

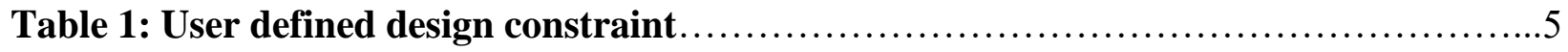

Table 2: Specifications from Comparative Aircraft Study $\ldots \ldots \ldots \ldots \ldots \ldots \ldots \ldots \ldots \ldots \ldots$

Table 3: Additional Specifications from Comparative Aircraft Study $\ldots \ldots \ldots \ldots \ldots \ldots \ldots \ldots 7$

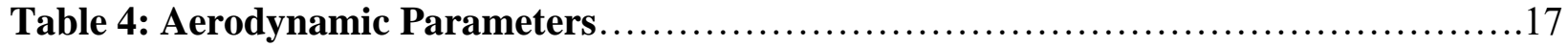




\section{List of Figures}

Figure 1: Traditional design process of aircraft defined by Corke. Blue represents the

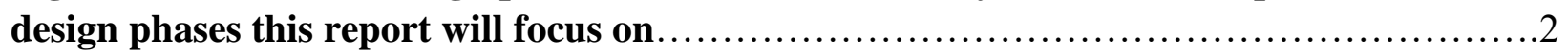

Figure 2: Advancement of the computer through time as it relates to transistor...........4

Figure 3: Methodology of the conceptual design process..............................6

Figure 4: General Atomics' MQ-1 Predator.......................................

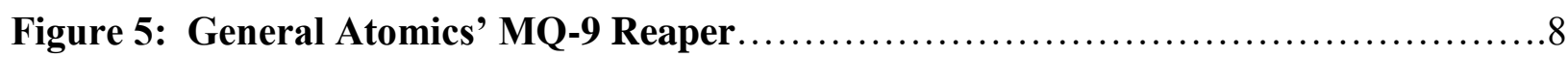

Figure 6: Weight as a function of power for turbocharge engines.......................

Figure 7: Mission outline used for the fuel fraction in the computer program............10

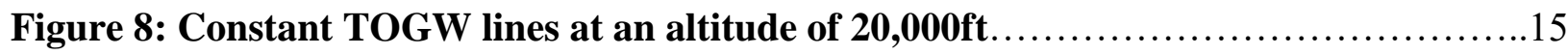

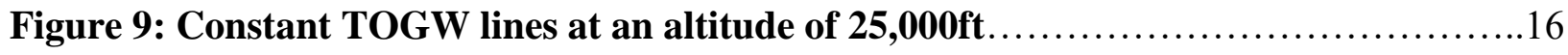

Figure 10: CAD model of the cluster computer.................................22

Figure 11: Flowchart representing the workflow through the cluster computer..........23

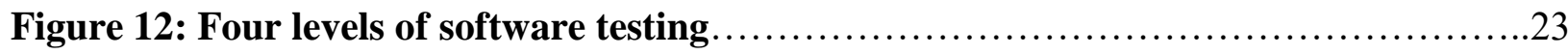

Figure 13: Limits of the design constraints from regression testing .....................24

Figure 14: Boundary testing results of the user defined design constraints................25

Figure 15: Variant results with design constraints of $R=650 \mathrm{nmi}, E=10 \mathrm{hrs}, V_{\text {crs }}=200 \mathrm{kts}$,

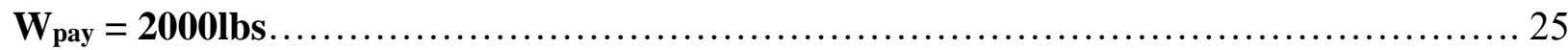

Figure 16: $T O G W$ constants for $R=650 \mathrm{nmi}, E=10 \mathrm{hrs}, V_{\text {crs }}=200 \mathrm{kts}, W_{\text {pay }}=2000 \mathrm{lbs} \ldots .26$ Figure 17: Variant results with design constraints of $R=250 \mathrm{nmi}, E=15 \mathrm{hrs}, V_{\text {crs }}=150 \mathrm{kts}$,

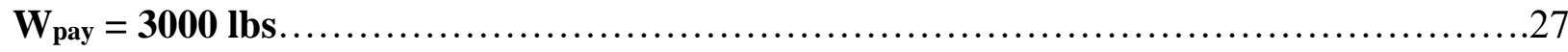

Figure 18: $T O G W$ constants for $R=250 \mathrm{nmi}, E=15 \mathrm{hrs}, V_{\text {crs }}=150 \mathrm{kts}, W_{\text {pay }}=3000 \mathrm{lbs} . .28$

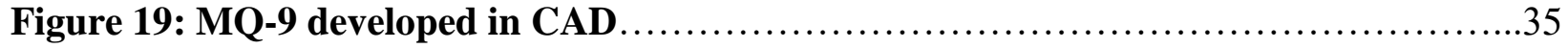

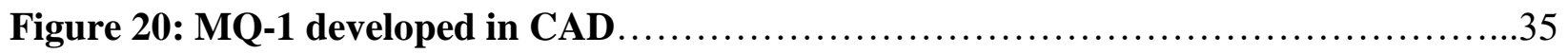

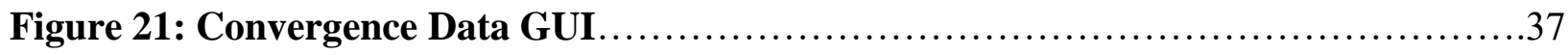

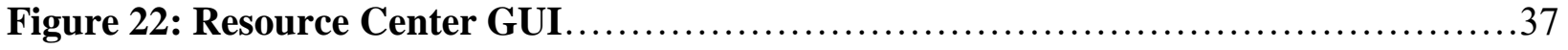




\section{List of Symbols}

\section{Symbol}

$a_{x}$

$A p$

AR

$A R_{\text {eff }}$

$B$

$C_{d 0}$

$C_{\text {Dofus }}$

$\mathrm{CDOHT}$

CDOVT

$C_{D 0 \text { wing }}$

$C_{F}$

$\mathrm{c}_{\mathrm{f}}$

$C_{L}$

$\bar{C}_{L}$

$C_{L \alpha}$

$C L_{c r}$

$C L_{L / D \max }$

$C_{\text {lmax }}$

$c_{r}$

$c_{t}$

$C_{H T}$

$C_{V T}$

$D$

$D_{x}$

$e$

$F_{f}$

$h$

$h_{T R}$

$i_{w}$

L/D crs

$L / D_{\max }$

$l_{H T}$

$L_{t}$

$l_{V T}$

$L_{x}$

m.a.c.

$N_{z}$

$P_{\text {reqd }}$

$P_{S H P}$

\section{Definition}

Units

$\mathrm{x}$ component of acceleration

$\mathrm{ft}^{2} / \mathrm{sec}$

area of the propeller disk

$\mathrm{ft}$

aspect ratio

effective aspect ratio

wing span

zero lift drag coefficient

zero lift drag coefficient of fuselage

zero lift drag coefficient of horizontal tail

zero lift drag coefficient of vertical tail

zero lift drag coefficient of wing

coefficient of friction

chord of flap

coefficient of lift

ratio of $C L_{c r}$ over $C L_{L / D \max }$

wing angle of attack lift coefficient

coefficient of lift at cruise

coefficient of lift at $L / D_{\max }$

maximum lift coefficient

chord at wing root

chord at wing tip

horizontal tail coefficient

vertical tail coefficient

drag

x component of drag

Oswald Efficiency Factor

friction force

height of wing above ground

transition height

incidence of the wing

lift over drag at cruise

max. lift over drag ratio

length from wing $1 / 4$ m.a.c to h. tail $1 / 4$ m.a.c

length from wing $1 / 4$ m.a.c to tail $1 / 4$ m.a.c

length from wing $1 / 4$ m.a.c to v. tail $1 / 4$ m.a.c

$\mathrm{x}$ component of lift

mean aerodynamic chord

ultimate load factor

required shaft horsepower

shaft horsepower
---

$--$

$\mathrm{ft}$

---

$---$

$---$

$---$

$---$

$---$

$\mathrm{ft}$

$---$

$---$

$---$

---

$---$

$---$

$\mathrm{ft}$

$\mathrm{ft}$

$---$

lbs

lbs

lbs

$\mathrm{ft}$

$\mathrm{ft}$

deg

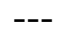

$---$

$\mathrm{ft}$

$\mathrm{ft}$

$\mathrm{ft}$

lbs

$\mathrm{ft}$

---

HP

HP 


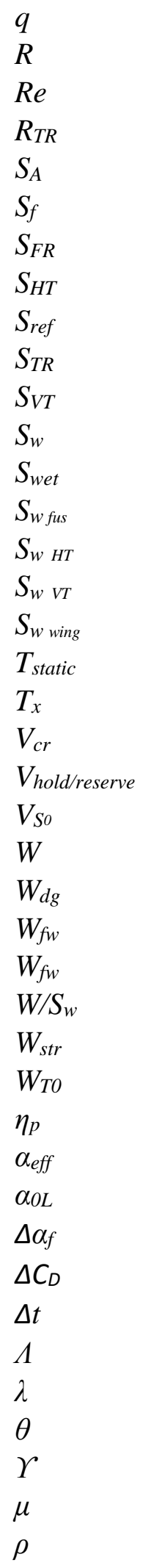

dynamic pressure psf

range n.m.

Reynolds Number

transition phase arc length $\mathrm{ft}$

approach distance $\quad \mathrm{ft}$

fuselage wetted area $\quad \mathrm{ft}^{2}$

free roll distance $\quad \mathrm{ft}$

horizontal tail area $\quad \mathrm{ft}^{2}$

wing reference area $\quad \mathrm{ft}^{2}$

transition distance $\quad \mathrm{ft}$

vertical tail reference area $\quad \mathrm{ft}^{2}$

trapezoidal area $\quad \mathrm{ft}^{2}$

wetted area $\mathrm{ft}^{2}$

wetted area of the fuselage $\mathrm{ft}^{2}$

wetted area of the horizontal tail $\mathrm{ft}^{2}$

wetted area of the vertical tail $\mathrm{ft}^{2}$

wetted area of the wing $\mathrm{ft}^{2}$

static thrust lbs

$\mathrm{x}$ component of thrust lbs

cruising velocity knots

holding and reserve velocity knots

stall velocity $\mathrm{ft} / \mathrm{sec}$

weight lbs

design gross weight lbs

weight of fuel in wing lbs

weight of fuel in wing lbs

wing loading $\quad \mathrm{lbs} / \mathrm{ft}^{2}$

structural weight lbs

take-off weight lbs

propeller efficiency ---

effective angle of attack deg

zero lift angle of attack deg

change in angle of flaps deg

change in drag coefficient ---

change in time sec

wing sweep deg

taper ratio ---

pitch angle deg

climb angle deg

friction coefficient
density
$\mathrm{sl} / \mathrm{ft}^{3}$ 


\section{Introduction}

The conceptual design of an aircraft is a very extensive and sensitive process. The aviation industry constantly attempts to improve previous designs and produce more efficient aircraft to maximize output, minimize costs, and improve overall performance. The goal of this design effort is to formulate a method to maximize efficiency in the creation of an UAV. This design method will allow parameters such as takeoff gross weight and takeoff or landing distance to be minimized while maximizing the efficiency of the aircraft for a set of desired performance characteristics. Other more basic design methods may yield an inefficient aircraft which is overpowered, excessively heavy, or includes unnecessary design measures due to the design being constrained to one parameter.

\section{Problem Statement}

A computer algorithm is developed to apply a unique iterative methodology for the design of MALE, cruising altitude $<35,000 \mathrm{ft}$, UAVs with the assistance of inexpensive cluster computing. This methodology will produce a family of aircraft that will calculate a specific set of design variables such as $W / S$ wing loading, $W / P$ (power loading), $A R$ (aspect ratio) and cruise altitude to determine the aircraft with the lowest TOGW that meet design constraints set by the user such as endurance, range as well as others. A cluster computer, developed from a series of Raspberry PIs, was designed to ease this computational process.

\section{Background Research}

\subsection{Brief History of the UAV}

The development of the UAV can be traced back to the American Civil War when an inventor loaded a hot air balloon with explosives that was set to drop on enemy forces when a timed mechanism destroyed the balloon. One of the first aerial reconnaissance photos can be credited to the American military during the Spanish-American war when an engineer tied a camera to a kite that flew over enemy fortifications.

One of the biggest leaps in UAV design came during the end of WW2 when the NAZIS deployed the Vengeance Weapon 1, also known as the V1. This weapon was designed to fly 
explosives across the channel and crash into British cities. The effectiveness of this missile during that war is debatable, however, its development throughout the $20^{\text {th }}$ century has completely revolutionized the battlefield ${ }^{1}$.

\subsection{Conventional Design Approach}

The overall design process of aircraft can be expressed in Figure 1 below.

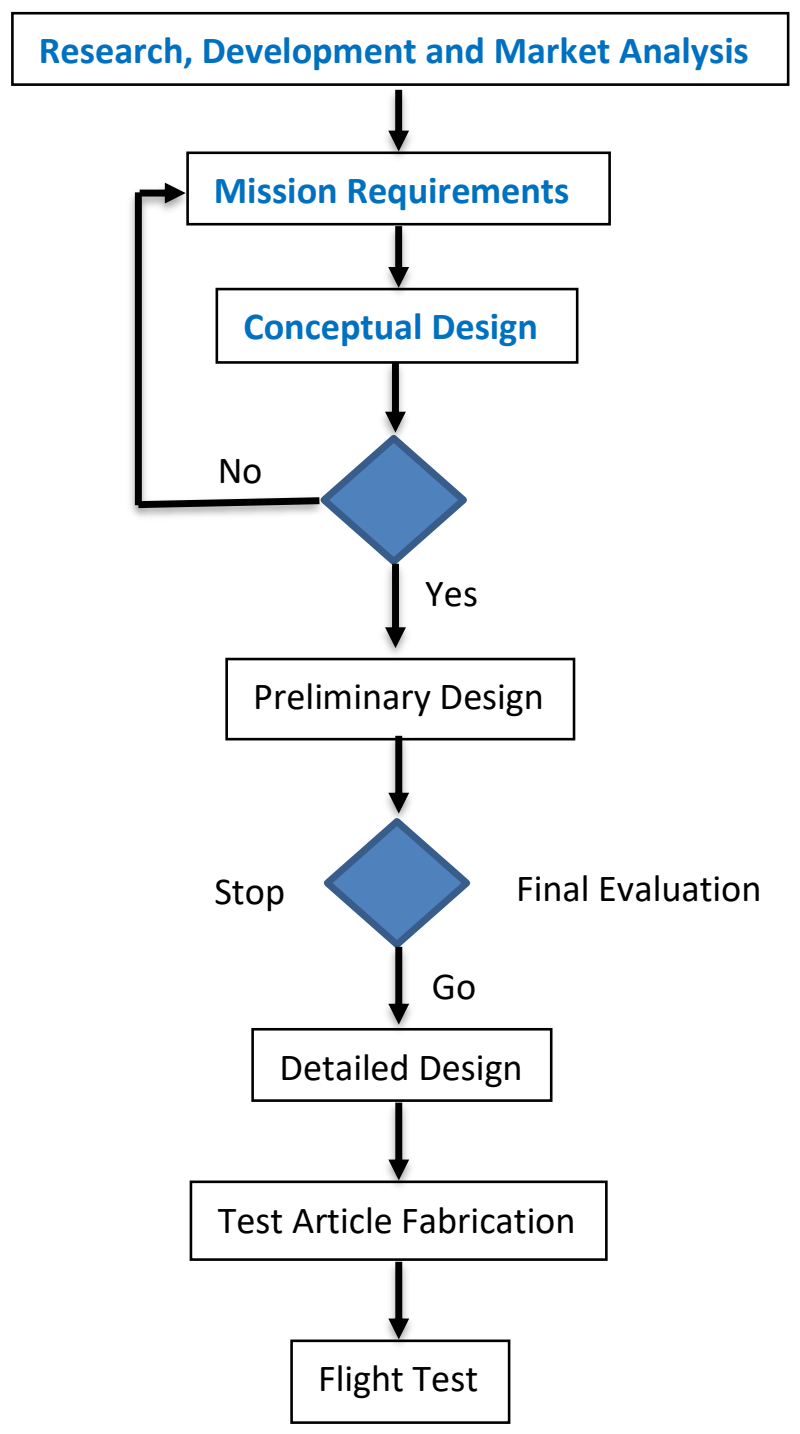

Figure 1: Traditional design process of aircraft defined by Corke. Blue represents the design phases this report will focus on. ${ }^{4}$

It starts with a comparative aircraft study to gather important aircraft characteristics for the initial calculations. Additionally, market research is conducted to determine if the type of aircraft 
the user wishes to develop is economically feasible. The next step is to define the type of mission this aircraft will carry out. The aircraft may solely conduct aerial reconnaissance for military applications, transport cargo/people domestically/internationally or the aircraft may be available to civilians for recreational use only. Defining the mission will lead to defining design constraints, with some tolerance, such as takeoff/landing distance, range, endurance, cruise altitude and so on. The next step is to move into the conceptual design phase of the aircraft by calculating design variables such as $T O G W, L / D_{\max }, A R$ etc. while attempting to hold the design constraints constant. As seen in Figure 1 above, this is an iterative process as the design constraints defined in the mission requirements may have to be adjusted. The next phase is the preliminary design which will focus on creating a basic proof of concept. This will involve performing calculations focused around flight mechanics, structure stresses and stability and control calculations. At the conclusion of this step, a design review is performed to ensure the current design is feasible practically and economically. After the review has passed, the detailed design process will then focus on specific components of the aircraft such as the tail design, propulsion system, landing gear, control surfaces, equipment and subsystems and testing the integration between all these components. Wind tunnel testing and CFD is also done at this stage. The final stage is the flight testing were test pilots and a team of engineers will conduct a series of maneuvers to define the flight envelope and to make sure the aircraft will successfully perform its overall mission ${ }^{4}$.

\subsection{Cluster Computing}

\subsubsection{Moore's Law}

Explosion in the development of supercomputers and their uses by hobbyist, students, universities etc. can be heavily contributed to the dramatic price drop of these awesome machines due to Moore's law. Moore's law, developed by Gordon Moore in 1965, states that the number of transistors per silicon chip will double every year ${ }^{17}$. Figure 2 below illustrates the advancement. 


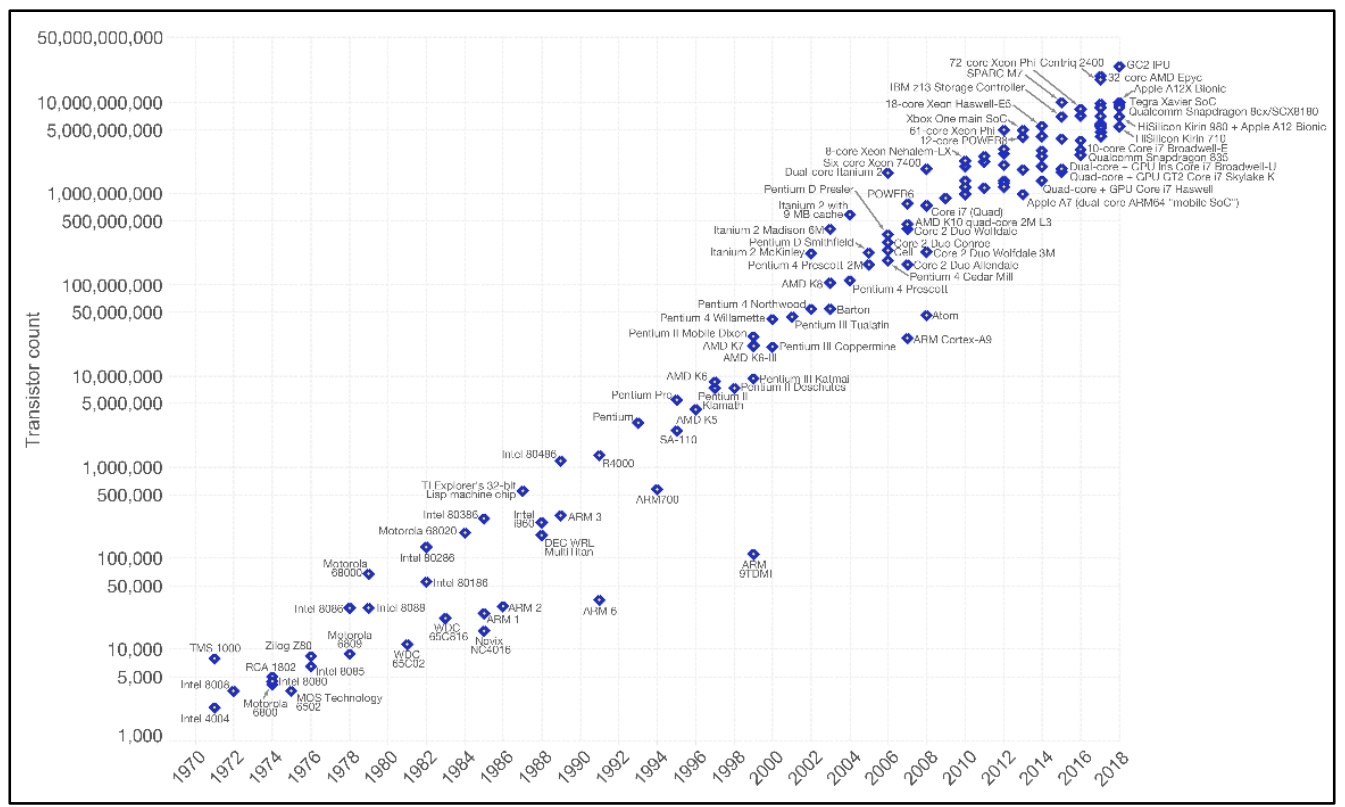

Figure 2: Advancement of the computer through time as it relates to transistor ${ }^{17}$

This law still roughly stands as it slowed down from 12 to 18 months. However, this law is expected to continue throughout the $21^{\text {st }}$ century as the size of transistors continues to shrink and with their advancements such as the development of the $3 \mathrm{D}$ transistor ${ }^{17}$. The results from this law can be linked to the drop-in cost of computing and the availability of computing power to researchers with a lack of funding.

\subsubsection{Aircraft Design and Supercomputers}

Designing aircraft using supercomputers is not a new concept: universities, aircraft industries and government agencies such as NASA are currently using supercomputers to generate and test new designs of aircraft. Boeing purchased the global supercomputer leader, Cray Inc., and utilized its processing power of billions of operations per second to build the very successful 787 Dreamliner ${ }^{5}$. NASA is currently using a supercomputer to help improve propulsion designs. A team of engineers are using supercomputers to develop a radical new wing to cut down on weight which can save the airline industry millions of gallons of fuel per year. A team of engineers used this supercomputer to redevelop the wing of a Boeing 777 that weighed 5\% less. These are just some examples how supercomputers are utilized by Aerospace Engineers to solve the complex problem of optimizing aircraft design ${ }^{19}$. 


\section{Methodology}

\subsection{Process of Conceptual Design}

In order to accurately carry out multiple calculations at once, an iterative process is used. The process begins with the selection of the user defined design constraints as stated in the above section. The user will be able to select the desired range, endurance, cruise velocity and payload weight. These design constraints can be seen in Table 1 below.

Table 1: User defined design constraints

\begin{tabular}{|l|}
\hline Endurance $(E)$ \\
\hline Range $(R)$ \\
\hline Cruise Alt. $\left(V_{c r s}\right)$ \\
\hline Payload Weight $\left(W_{p}\right)$ \\
\hline
\end{tabular}

A comparative aircraft study is then conducted to establish a jumping-off point by using the performance characteristics for initial calculations. Such characteristics as structural factor, wing span, lift over drag ratio are just some that are utilized. Once design constraints are chosen and structural factor and lift over drag ratio are estimated an initial aspect ratio, wing loading and cruise altitude are chosen.

From these inputs and the design constraints, a gross takeoff weight is calculated using the fuel fraction method. Once takeoff weight is determined, the specific structural weights are calculated as well as the aerodynamic performance of the aircraft using general design methods and a computer aided design of the fuselage and tail sections. Upon completion of the structural and aerodynamic calculations, the values of lift to drag ratio and structural factor are reviewed in comparison to initial estimates. If these values do not match, the initial values are altered, and the above analysis is repeated yielding a new design. This process is continued until the initial estimate of lift to drag ratio and structural factor (termination criteria) match the final calculations of those parameters. Once values of structural factor and lift to drag ratio converge, the aerodynamic data yields a required power loading.

With an initial design using a specified wing loading, aspect ratio and cruise altitude are created and finalized, the wing loading is altered, and the above process is repeated for that new wing loading. This process is done for wing loadings varying from ten to forty in increments of 
five in order to create a family of aircraft which all have the same aspect ratio at some cruise altitude.

With a family of aircraft of the same aspect ratio generated, the above process is repeated using a different aspect ratio. With this new aspect ratio, an additional family of aircraft of various wing loadings are generated. This analysis is performed for aspect ratios ranging from ten to thirty in increments of 5 . The entire is then repeated for a different cruise altitude that ranges from $20,000 \mathrm{ft}$ to $60,000 \mathrm{ft}$ in increments of $5,000 \mathrm{ft}$.

A plot is then generated depicting the wing loading of the various designs versus their respected power loading, $V_{c r s}$ and $A R$. On this plot, lines of constant gross takeoff weight are modeled. Additionally, lines of respected takeoff distance and landing distance are generated. From the intersection of these lines, a design which meets all restraints can be selected thus optimizing all the above parameters.

The above process is also graphically depicted in a flow chart which can be seen in Figure 3.

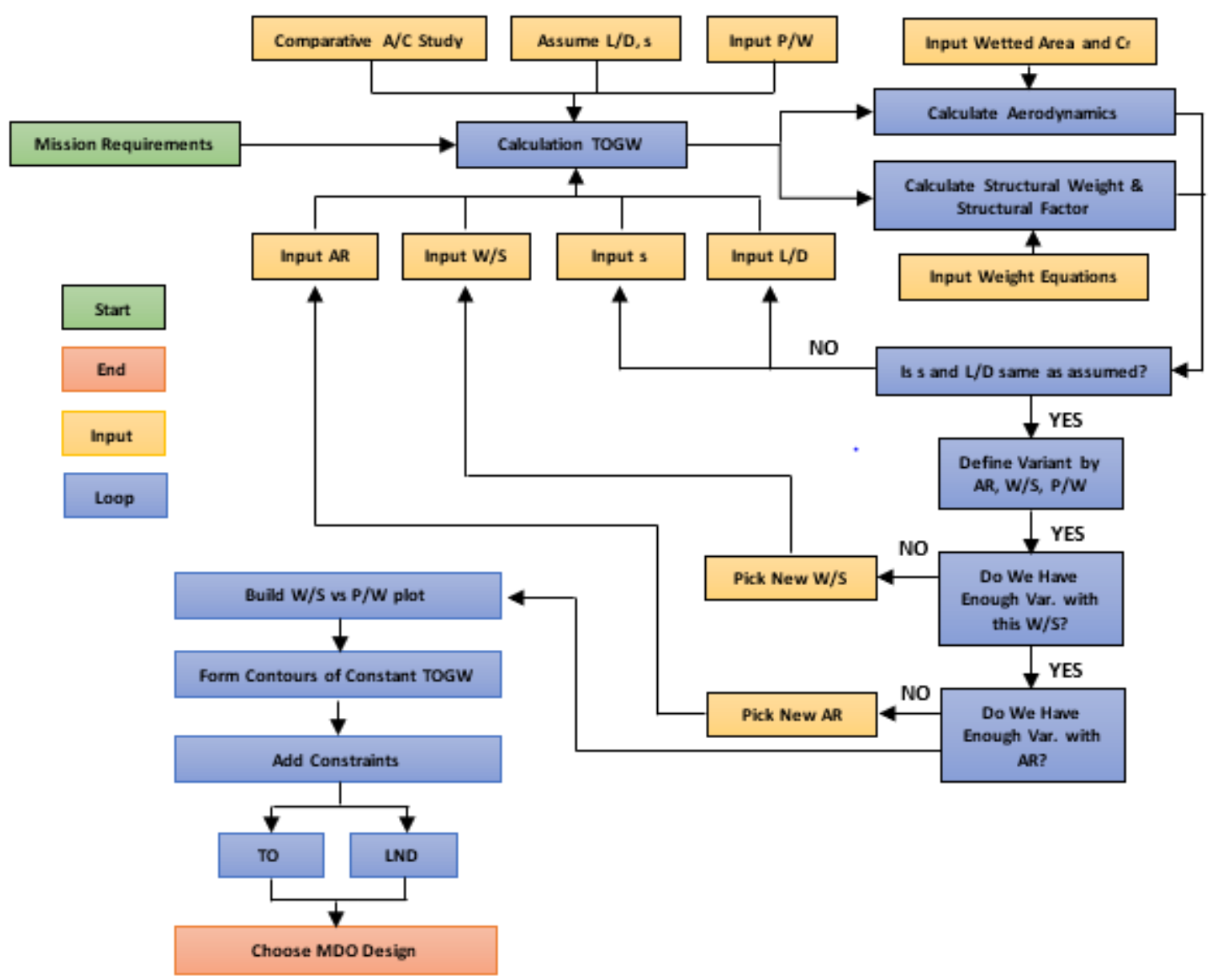

Figure 3: Methodology of the conceptual design process 


\subsection{Preliminary Calculation of Parameters}

\subsubsection{Comparative Aircraft Study}

In order to begin the design process several estimates of design parameters must be made. This includes but is not limited to total length and width of the fuselage, wing size, tail size and configuration. In order to be relatively accurate with estimates for these parameters, several previously designed aircraft of similar size and mission were considered. These aircraft were the MQ-9 Reaper and MQ-1 Predator as seen in Figures 4 and 5 below. Data collected and used to begin the design process is summarized in Tables 2 and 3 below.

Table 2: Specifications from Comparative Aircraft Study ${ }^{11,12}$

\begin{tabular}{|c|l|c|c|c|c|}
\hline & \multicolumn{1}{|c|}{ Aircraft } & $\begin{array}{c}\text { Range } \\
\text { (nmi) }\end{array}$ & $\begin{array}{c}\text { Max. Alt. } \\
\text { (ft) }\end{array}$ & $\begin{array}{c}\text { TOGW } \\
\text { (lbs) }\end{array}$ & $\begin{array}{c}\text { Endurance } \\
\text { (hrs) }\end{array}$ \\
\hline \multirow{2}{*}{ HALE } & RQ-4 Global Hawk & 12,300 & 60,000 & 32,250 & 34 \\
\cline { 2 - 6 } & Altus II & 400 & 60,000 & 2,130 & 24 \\
\hline \multirow{2}{*}{ MALE } & MQ-9 Reaper & 1,000 & 50,000 & 10,500 & 14 \\
\cline { 2 - 6 } & MQ-1 Predator & 675 & 25,000 & 2,250 & 24 \\
\hline
\end{tabular}

Table 3: Additional Specifications from Comparative Aircraft Study ${ }^{11,12}$

\begin{tabular}{|c|l|c|c|c|}
\hline & \multicolumn{1}{|c|}{ Aircraft } & Powerplant & $\begin{array}{c}\text { Fuel } \\
\text { Capacity }\end{array}$ & $\begin{array}{c}\text { Payload } \\
\text { (Ibs) }\end{array}$ \\
\hline \multirow{2}{*}{ HALE } & $\begin{array}{l}\text { RQ-4 Global } \\
\text { Hawk }\end{array}$ & F-137-RR-100 turbofan engine & 17,300 lbs & 3,000 \\
\cline { 2 - 5 } & Altus II & $1 \times$ Rotax 912 4-cyl w/turbocharger 100hp & 92 gals & 330 \\
\hline \multirow{2}{*}{ MALE } & MQ-9 Reaper & $\begin{array}{c}1 \times \text { Honeywell TPE331-10 turboprop } \\
900 h p\end{array}$ & $2,000 \mathrm{lbs}$ & 3,800 \\
\cline { 2 - 5 } & MQ-1 Predator & $1 \times$ Rotex 914F four-cylinder engine 115hp & $665 \mathrm{lbs}$ & 450 \\
\hline
\end{tabular}




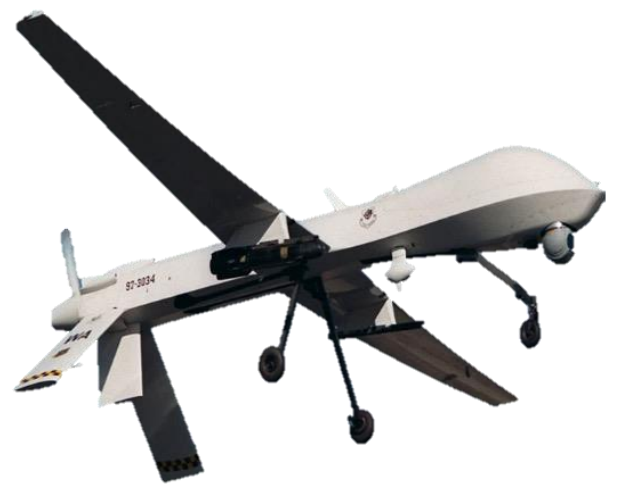

Figure 4: General Atomics' MQ-1 Predator ${ }^{11}$

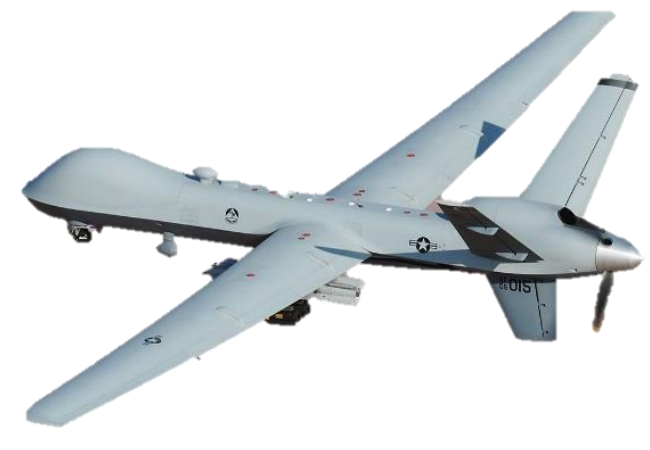

Figure 5: General Atomics' MQ-9 Reaper ${ }^{12}$

Due to the classification of these aircraft, most of their characteristics are not available to the general public. As a result, rough estimates had to be made in some circumstances. In other circumstances, such as the $S_{w e t}$, the fuselage was recreated in a computer aided design program that was able to provide such a value. Please refer to Appendix A, Figures 21 and 22 for a depiction of the CAD models of the MQ-1 Predator and MQ-9 Reaper.

\subsubsection{Engine Study}

A comparative study was conducted for dozens of Lycoming and Continental engines. The different types of engines consisted of mainly turbocharged engines. A turbocharged engine uses a turbine for forced induction. Dozens of engines were collected along with their specifications. The power of the Lycoming and Continental engines were plotted against their weights to later determine the most efficient engine based on the power needed for the aircraft and its lowest dry weight. Figure 6 below represents all the Lycoming and Continental turbocharged engines. The linear best fit line was also added. Please refer to Appendix $\mathrm{C}$ for specifications collected on all the analyzed engines. 


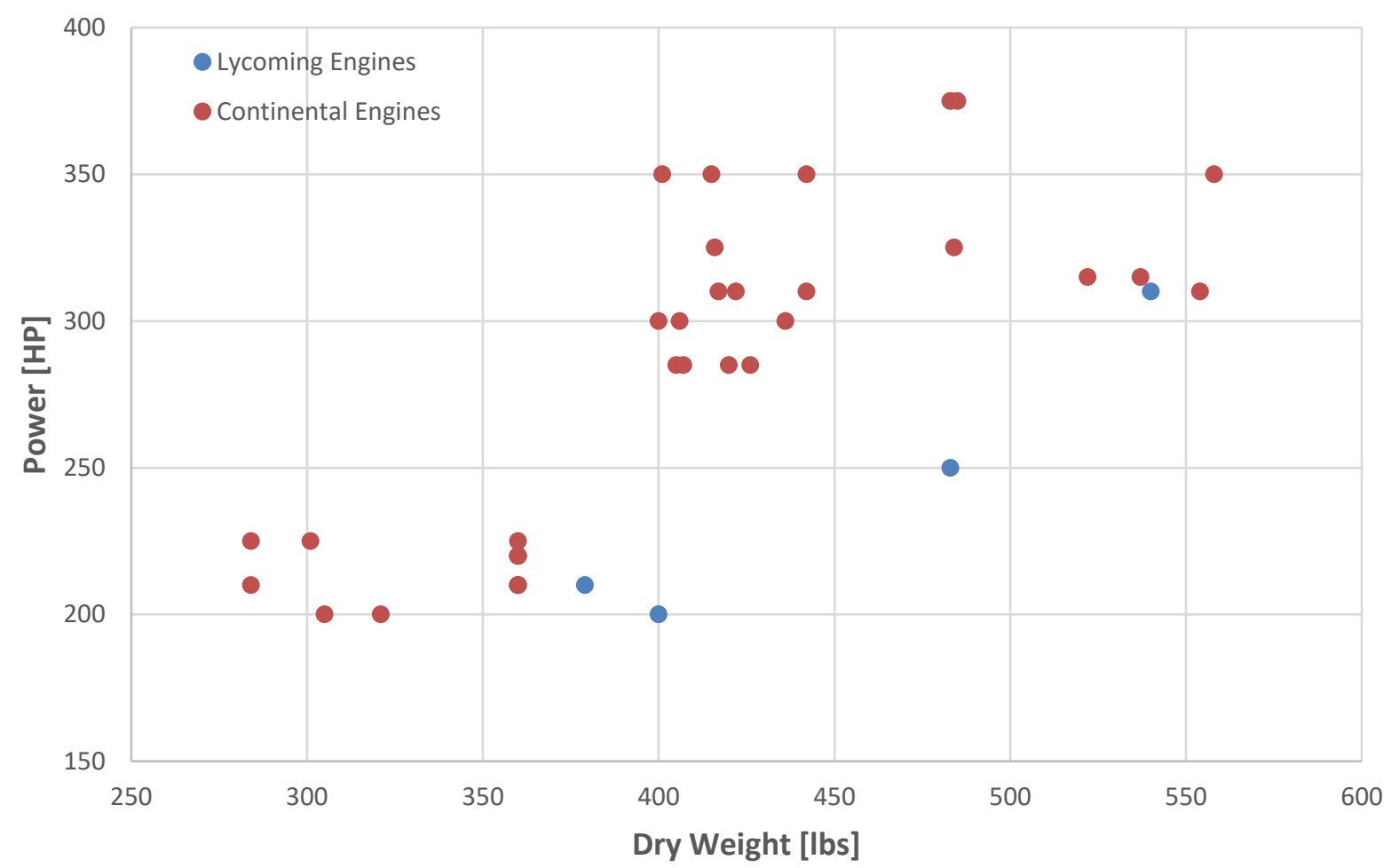

Figure 6: Weight as a function of power for turbocharged engines ${ }^{3}$

\subsubsection{Initialization of Take-Off Gross Weight}

In order to make initial calculations, estimates must be made of some key parameters to serve as a "jump-off" point. In this manner, the estimated parameters can be continuously refined to produce the best final result. For the purposes of this process, the parameters that are to be initially estimated are the zero-lift drag coefficient, structural factor, and cruise lift-to-drag ratio.

With these preliminary estimates completed, it is then possible to calculate early aerodynamic parameters, which will allow for the calculation of the takeoff gross weight. Several such parameters are found via Equations 4.1, 4.2, and 4.3 below.

$$
\begin{gathered}
\left(\frac{L}{D}\right)_{\text {max }}=\frac{1}{2} \sqrt{\frac{\pi A R e}{C_{D_{0}}}} \\
C_{L_{\left(\frac{L}{D}\right)_{\max }}}=\sqrt{\pi A R e C_{D_{0}}}
\end{gathered}
$$




$$
V_{\text {hold }}=\sqrt{\frac{\left(W / S_{r}\right)}{\frac{1}{2} \rho C_{L_{\left(\frac{L}{D}\right)_{\max }}}}}
$$

The fuel fraction method is the technique used to estimate the aircraft takeoff gross weight. It involves estimating the relative amount of fuel an aircraft will use during a mission. It describes the change in weight an aircraft experiences when it consumes fuel during a given phase of flight.

The distinct phases of flight are as follows for this computer program.

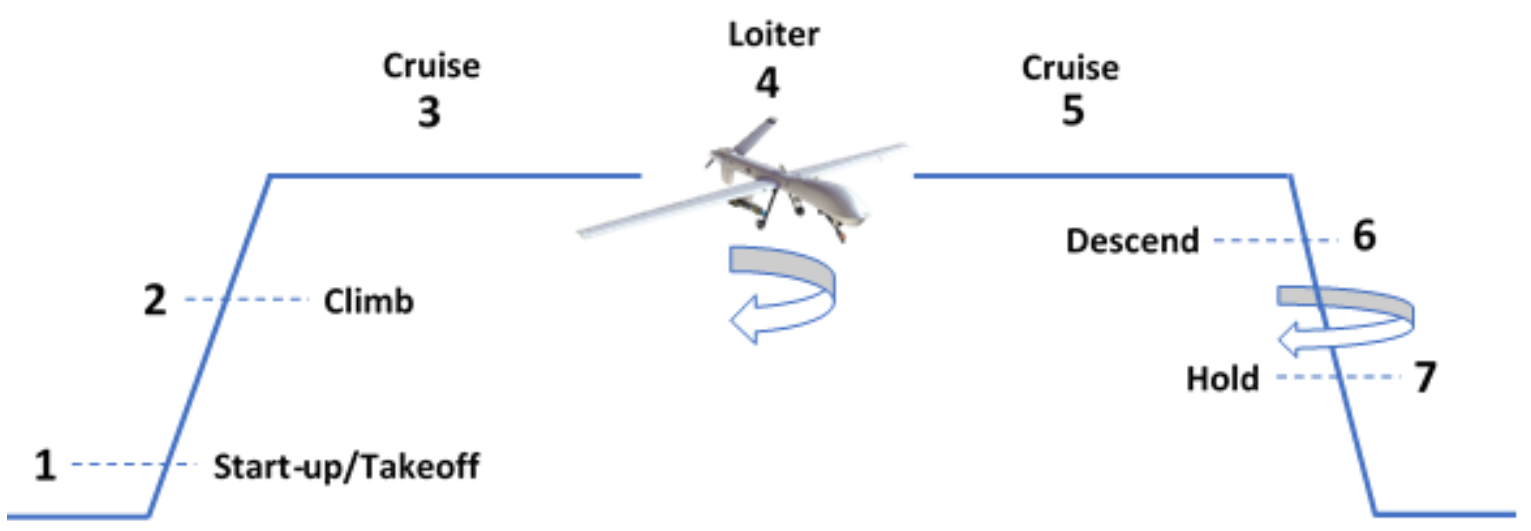

Figure 7: Mission outline used for the fuel fraction in the computer program

1) Start-up, Taxi, Run-up, Takeoff

2) Climb/Accelerate

3) Cruise

4) Loiter

5) Cruise

6) Holding or Reserve

7) Decent/Landing

For the first, second, and seventh phases of flight, simple ratios are used to determine the fuel required for each of the phases. For example, it is estimated that the aircraft exits the first phase of flight with $98 \%$ of the weight with which it entered that phase--that is, the aircraft becomes $2 \%$ lighter due to fuel consumption.

For the third and fifth phases of flight, a more complex relationship is used. This relationship relies on the Breguet Range Factor. The Breguet Range Factor encompasses the 
efficiency of the propeller, the cruise lift-to-drag ratio, and the specific fuel consumption of the engine, in order to produce a value that reflects the aircraft's relative range. It is calculated via the following equation:

$$
W_{\text {final }}=\left(1-\frac{1}{e^{\frac{R}{B R F}}}\right) W_{\text {initial }}
$$

The fourth phase of flight also uses a special relationship that uses a quantity known as the Breguet Endurance Factor. This factor includes the maximum lift-to-drag ratio, the specific fuel consumption of the engine, and the holding velocity in order to give a value that shows the aircraft's relative endurance. Equation 4.5 shows this relationship below.

$$
W_{\text {final }}=\left(1-\frac{1}{e^{\frac{E}{B E F}}}\right) W_{\text {initial }}
$$

Evaluating each phase of flight from first to last gives an estimate of the comparative fuel weight the aircraft must be able to accommodate. The takeoff gross weight is found based on the selected structural factor, as shown below in Equation 4.6, which compares the required structural weight to the overall takeoff gross weight.

$$
s=\frac{W_{s t r}}{W_{T O}}
$$

Next, additional aerodynamic and geometric characteristics may be determined after the calculation of dynamic pressure using Equation 4.7.

$$
q=\frac{1}{2} \rho V^{2}
$$




\subsubsection{Calculation of Aerodynamics}

Using some key assumptions about the layout of the aircraft and general shape of the wing, it is possible to find several geometric parameters, Equations 4.8, 4.9, 4.10 and 4.11, pivotal in calculating aerodynamic characteristics:

$$
\begin{gathered}
S_{r}=\frac{W_{T O}}{\left(\frac{W}{S}\right)} \\
b=\sqrt{\frac{A R}{S_{r}}} \\
c_{r}=\frac{2 b}{A R(1+\lambda)} \\
m a c=\frac{2}{3} c_{r} \frac{\left(1+\lambda+\lambda^{2}\right)}{(1+\lambda)}
\end{gathered}
$$

Calculation of the zero-lift drag on the aircraft is accomplished using the wetted areas of the aircraft components. These wetted areas are calculated in Equations 4.12, 4.13, 4.14, and 4.15.

$$
\begin{gathered}
S_{w_{\text {wing }}}=2.03 S_{r} \\
S_{w_{V T}}=c_{V T} \frac{b S_{r}}{l_{V T}} \\
S_{w_{H T}}=c_{H T} \frac{m a c S_{r}}{l_{H T}}
\end{gathered}
$$




$$
S_{w}=S_{w_{\text {wing }}}+S_{w_{f u s}}+S_{w_{V T}}+S_{w_{H T}}
$$

The wetted area of the fuselage was calculated from a design created in CAD program as explained above. Given the wetted areas of aircraft components, calculating the total zero-lift drag is no more than finding the effect of each component and adding them together, seen in Equation 4.16 .

$$
\begin{gathered}
C_{D_{0}}=\frac{c_{f} S_{w}}{S_{r}} F Q \\
C_{D_{0}}=C_{D_{0_{\text {wing }}}}+C_{D_{0_{f u s}}}+C_{D_{0_{V T}}}+C_{D_{0_{H T}}}
\end{gathered}
$$

The coefficient of lift at cruise flight condition is calculated using Equation 4.18 below.

$$
C_{L_{c r s}}=\frac{\left(\frac{W}{S_{r}}\right)}{q}
$$

The coefficient of drag at cruise flight condition is simply the sum of the zero-lift drag coefficient and the induced drag at cruise. It is calculated via Equation 4.19 below.

$$
C_{D_{c r s}}=C_{D_{0}}+\frac{C_{L_{c r s}}{ }^{2}}{\pi A R e}
$$

Using the normalized coefficient of lift, found in Equation 4.20, it is possible to recalculate the previously-estimated cruise lift-to-drag ratio. 


$$
\begin{gathered}
\overline{C_{L}}=\frac{C_{L_{c r s}}}{C_{L_{\left(\frac{L}{D}\right)_{\max }}}} \\
\left(\frac{L}{D}\right)_{c r s}=\frac{2 \overline{C_{L}}\left(\frac{L}{D}\right)_{\max }}{1+{\overline{C_{L}}}^{2}}
\end{gathered}
$$

Next, the power required to sustain flight at cruise is determined, shown below in Equation 4.22 .

$$
P_{\text {req }}=\frac{1}{550} \frac{V_{c r s}}{\eta_{p}}\left[\frac{W C_{D_{0}} q}{\left(\frac{W}{S_{r}}\right)}+\left(\frac{W}{S_{r}}\right) \frac{W}{q \pi A R e}\right]
$$

\subsubsection{Calculation of Weights}

Using Daniel Raymer's general aviation equations for component weights, it is possible to again calculate the total aircraft weight. The weight of the wing, horizontal tail, vertical tail and fuselage were calculated using the equations represented as Equation 4.23, 4.24, 4.25 and 4.26 below.

$$
\begin{gathered}
W_{\text {wing }}=0.036 S_{w}{ }^{0.758} W_{f w}{ }^{0.0035}\left(\frac{A}{\cos ^{2} \Lambda}\right)^{0.6} q^{0.006} \lambda^{0.04}\left(\frac{100 t / c}{\cos \Lambda}\right)^{-0.3}\left(N_{z} W_{d g}\right)^{0.49} \\
W_{\text {horizontal }}=0.016\left(N_{z} W_{d g}\right)^{0.414} q^{0.168} S_{h t}{ }_{\text {tail }}^{0.896}\left(\frac{100 t / c}{\cos \Lambda}\right)^{-0.12}\left(\frac{A}{\cos ^{2} \Lambda_{h t}}\right)^{0.043} \lambda_{h}{ }^{-0.02} \\
W_{\text {vertical }}^{\text {tail }}=0.073\left(1+0.2 \frac{H_{t}}{H_{v}}\right)\left(N_{z} W_{d g}\right)^{0.376} q^{0.122} S_{v t}^{0.873}\left(\frac{100 t / c}{\cos \Lambda_{v t}}\right)^{-0.49}\left(\frac{A}{\cos ^{2} \Lambda_{v t}}\right)^{0.357} \lambda_{v t}^{0.039}
\end{gathered}
$$




$$
W_{\text {fuselage }}=0.052 S_{f}^{1.086}\left(N_{z} W_{d g}\right)^{0.177} L_{t}{ }^{-0.051}(L / D)^{-0.072} q^{0.241}+W_{\text {press }}
$$

With this sum of these weights, structural factor can be recalculated as well. It is imperative that the estimated values of structural factor and cruise lift-to-drag ratio from the beginning of the process match their calculated values after the estimation of takeoff gross weight and calculation of aerodynamic parameters.

\subsubsection{TOGW Analysis}

In order to visualize the effects of gross weight on the performance characteristics of an aircraft, lines of constant gross weight were plotted on the power loading and wing loading graph which correspond to each aircraft variant. Using linear interpolation of the aircraft variant, respective power loading and wing loading values where found from which lines where plotted. These lines prove useful in later analysis as the lightest aircraft which satisfies a series of constraints can be identified. Examples of these lines can be seen in Figures 8 and 9 below.

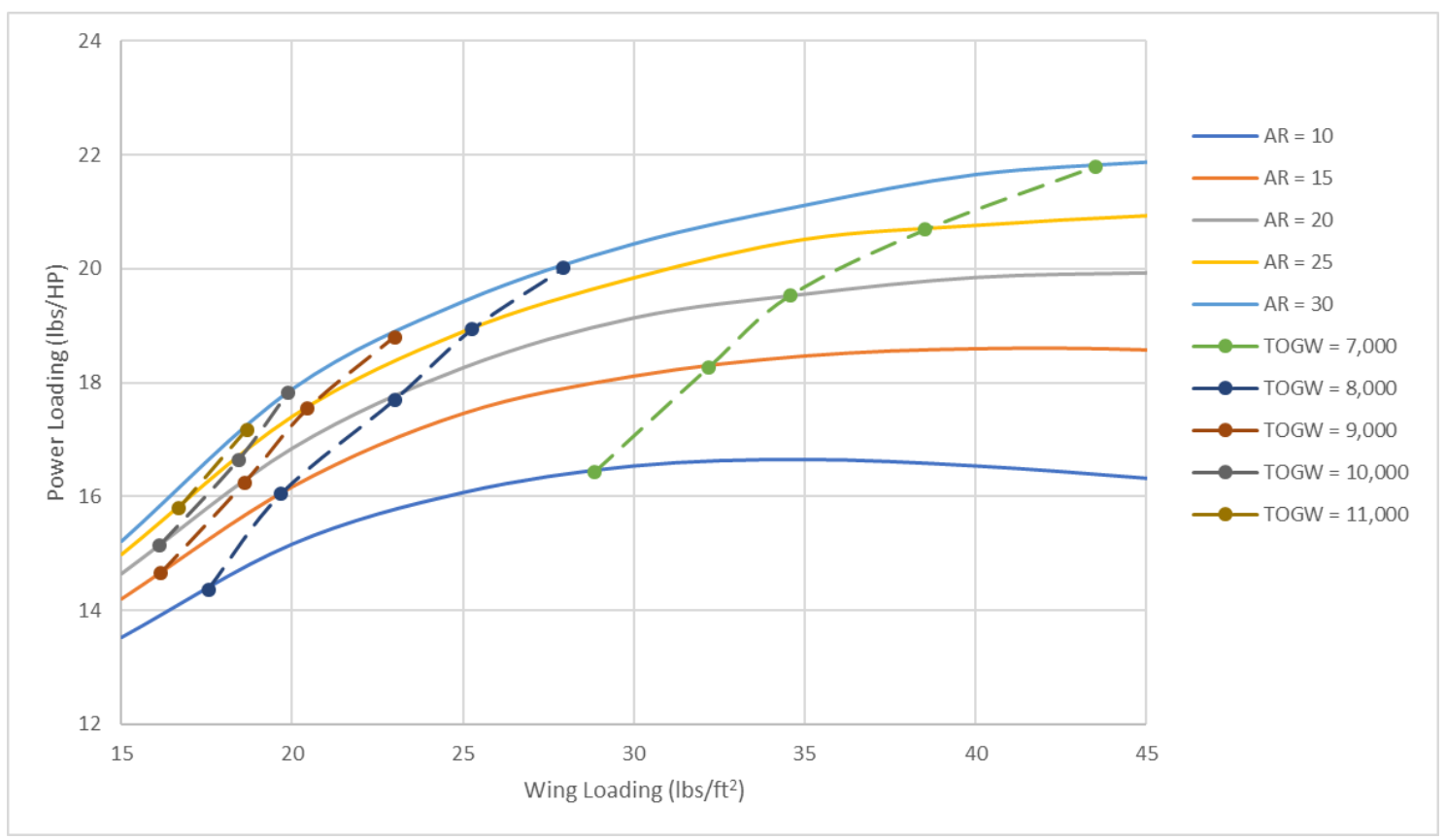

Figure 8: Constant TOGW lines at an altitude of 20,000ft 


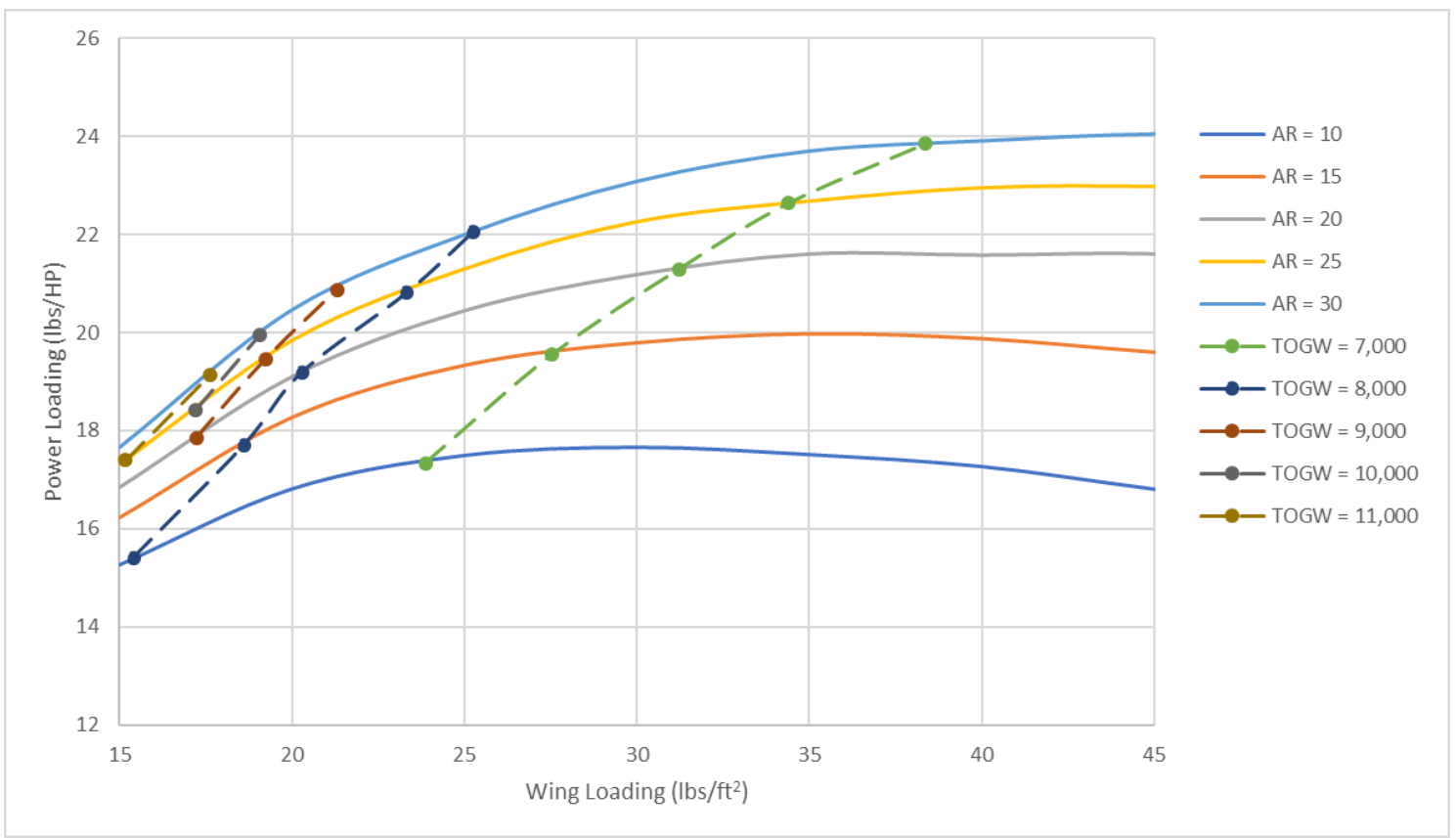

Figure 9: Constant TOGW lines at an altitude of 25,000ft

\subsubsection{Design Constraint Analysis}

\subsubsection{Takeoff Distance}

Takeoff distance can be resolved as a function of an aircraft's power loading, wing loading, and stall speed. Stall speed depends on the sizing of the wing and the airfoil selection. Airfoil selection will be held constant with a NACA 23015 airfoil. For this analysis takeoff distance will be modeled as the ground roll distance in which the aircraft accelerates to 1.2 times the stall speed, a typical rotation speed. The obstacle distance is designated at $50 \mathrm{ft}$.

Factors which are held constant in this analysis but pertain to take off distance include prop efficiency, lift curve slope, wing incidence angle, zero lift angle of attack, flap deflection, Oswald efficiency factor, maximum lift coefficient, and finally zero lift drag.

Prop efficiency was selected to be held at a constant value of 86 percent, similar to that of comparative aircraft. Lift curve slope for the NACA 23015 airfoil is 0.09, zero lift angle of attack is negative one degree, and maximum lift coefficient is 1.6. These values are found from the Theory of Wing Sections. Wing incidence angle was selected to be 1 degree which is similar to the comparative aircraft. A fowler flap was used via comparative aircraft analysis which added a base drag of 0.032 . Oswald efficiency factor is selected to be 0.85 corresponding to the wings taper 
ratio. Zero lift drag remains the same as in previous analysis with an increase of 0.025 for gear deflection. The above parameters are summarized in Table 4 below.

Table 4: Aerodynamic Parameters

\begin{tabular}{|l|c|}
\hline \multicolumn{2}{|c|}{ Aerodynamics } \\
\hline $\mathrm{e}$ & 0.85 \\
\hline $\mathrm{C}_{\mathrm{L} \alpha}\left(\mathrm{deg}^{-1}\right)$ & 0.09 \\
\hline $\mathrm{i}_{\mathrm{W}}(\mathrm{deg})$ & 1 \\
\hline$\alpha_{0 \mathrm{~L}}(\mathrm{deg})$ & -1 \\
\hline$\delta_{\text {flaps }}(\mathrm{deg})$ & 0 \\
\hline$\eta_{\text {prop }}$ & 0.86 \\
\hline$\Delta \mathrm{C}_{\mathrm{D}, \text { flaps }}$ & 0.032 \\
\hline$\Delta \mathrm{C}_{\mathrm{D}, \text { gear }}$ & 0.0250 \\
\hline $\mathrm{C}_{\mathrm{D} 0}$ & 0.0167 \\
\hline $\mathrm{C}_{\mathrm{L}, \text { max }}$ & 1.6 \\
\hline
\end{tabular}

Modeling of takeoff distance ground roll is a relatively simple analysis using basic physics to model acceleration, velocity, and displacement. Using excel, a time vector is created with increasing time by a selected increment.

The numerical integration used to calculate the takeoff length is a function of this time step $(\Delta t)$, acceleration of the aircraft in the $\mathrm{x}$ direction, magnitude of velocity along with its components, thrust, lift, drag, friction, pitch, angle of attack and flight path angle. At $t=0$ seconds, the velocity, $S_{x}$, and angle of attack of the aircraft are all at equal to zero. However, there is static thrust from the engines. This was calculated using Equation 4.27 below.

$$
T_{\text {static }}=\left(P \eta_{p} 550 \sqrt{2 \rho A_{d}}\right)^{2 / 3}
$$

The effective angle of attack was then calculated. This is represented by Equation 4.28 below. 


$$
\alpha_{e f f}=\left(\theta-\gamma+i_{w}-\alpha_{0 L}+\Delta \alpha_{f}\right)
$$

Effective angle of attack is a non-zero parameter at these static conditions because there is incidence on the wing and is has a zero-lift angle of attack due to its airfoil properties. The effective aspect ratio in ground effect was then calculated using Equation 4.29 below.

$$
A R_{G E}=\frac{A R}{\sqrt{\frac{2 h}{b}}}
$$

The coefficient of drag was then calculated using Equation 4.30 below. The extra terms represent the change in drag due to the flaps and the landing gear on the aircraft as previously mentioned.

$$
C_{D}=C_{D_{0}}+\frac{C_{L}}{\pi A R e}+\Delta C_{D_{\text {gear }}}+\Delta C_{D_{\text {flap }}}
$$

The coefficient of drag can then be used to calculate the drag of the aircraft along with its components. Equation 4.31 represents the drag of the aircraft. At $t=0$, this value will be zero because there is no dynamic pressure term. Due to the drag being zero, the drag components will also go to zero at this moment. The drag components in the $x$ can be represented by Equation 4.32 below.

$$
D=C_{D} q S_{r}
$$




$$
D x=D \cos (Y)
$$

The rolling friction force for the aircraft is now calculated using Equation 4.33 below. This force decreases slightly as the aircraft makes its way down the runway due to lift increasing with velocity. After the rolling phase ends and the aircraft is airborne, this value goes directly to zero.

$$
F_{f}=\mu(W-L)
$$

The $\mathrm{x}$-component of acceleration of the aircraft is finally solved using Equations 4.34 below. There is no acceleration in the y-direction until the aircraft is pitched upwards which creates a velocity and acceleration vector in the y-direction which is not included in this analysis.

$$
a_{x}=\frac{g}{w}\left(T_{x}-L_{x}-D_{x}-F_{f}\right)
$$

After the acceleration component is calculated, the integration process begins. The velocity in the $\mathrm{x}$-direction is then calculated using Equation 4.35 below. This equation uses the acceleration calculated in the last time step. This is repeated for every time step.

$$
V_{1 x}=V_{0 x}+a_{x} \Delta t
$$

The distance in the $\mathrm{x}$-direction was then calculated using Equation 4.36 below. This equation also depends on the acceleration component from the previous time step. 


$$
S_{1 x}=S_{0 x}+\frac{V_{1 x^{2}-V_{0 x}{ }^{2}}}{2 a_{x}}
$$

Using the velocity and distance components for this current time step, the lift, drag, friction, thrust and acceleration are calculated again. This process is repeated at time step intervals of 0.5 seconds and until 1.2 times the stall speed in the $\mathrm{x}$-direction is reached. Please refer to Appendix $\mathrm{C}$ for the spreadsheet layout for the takeoff performance.

\subsubsection{Landing Distance}

In order to model the full landing process of the aircraft, four segments including approach, translation, free roll, and braking were calculated independently. Approach landing distance was calculated using Equation 4.37.

$$
S_{A}=\frac{50-h_{T R}}{\tan \gamma}
$$

Translation distance was determined using Equation 4.38.

$$
S_{T R}=R_{T R} \sin \gamma
$$

Both translation and approach distances are dependent on the radius of transition, $R_{T R}$, and height of transition, $h_{T R}$, and as seen in Equations 4.39 and 4.40 means that these distances are primarily dependent on the stall speed of the aircraft.

$$
h_{T R}=R_{T R}-R_{T R} \cos \gamma
$$




$$
R_{T R}=\frac{\left(1.23 V_{S_{0}}\right)^{2}}{0.23 g}
$$

The free roll segment is directly related to the stall speed of the aircraft in the landing configuration, as seen in Equation 4.41.

$$
S_{F R}=3\left(1.15 V_{S_{0}}\right)
$$

The braking distance was determined using an iterative process. Using a time step of a half second, starting at the landing configuration stall speed the lift, friction, and drag forces acting on the aircraft are calculated at that time step and used to find the deceleration that is acting on the aircraft. From that acceleration using the basic trajectory equations, the velocity at the next time step and distance traveled are calculated.

By setting the total summation of landing distance to be $2,000 \mathrm{ft}$, holding power loading constant and solving for wing loading, a constraint line can be plotted on the original wing loading and power loading plot. Please refer to Appendix $\mathrm{C}$ for the spreadsheet of the landing used to calculate the landing performance

\subsection{Cluster Computer}

The development of the cluster computer stemmed from an efficiency issue that arose during the calculation of the wing weight using the analytical approach. The approach involved calculating the structural stresses the wing would encounter during flight and sizing the spars, ribs and strings accordingly. This is usually done in the preliminary design phase, however, to achieve a more accuracy in the structural factor calculation in the entire iteration process, this method was originally employed. The entire iterative method involved matching cycling through AR, W/S and cruise altitudes and matching the $s$ and $L / D_{c r s}$ from the previous iteration to the current iteration as explained in the above sections. This can involve thousands of iterations and due to the nature of intensity of the analytical method, the computational time rises from minutes to days. To combat 
this, a supercomputer can be employed to distribute the workload to decrease this time. Without the proper funding and access to already established supercomputers, a new inexpensive was developed by creating a cluster computer made up of cheap Raspberry PIs. Figure 10 below shows a CAD model of the cluster computer.

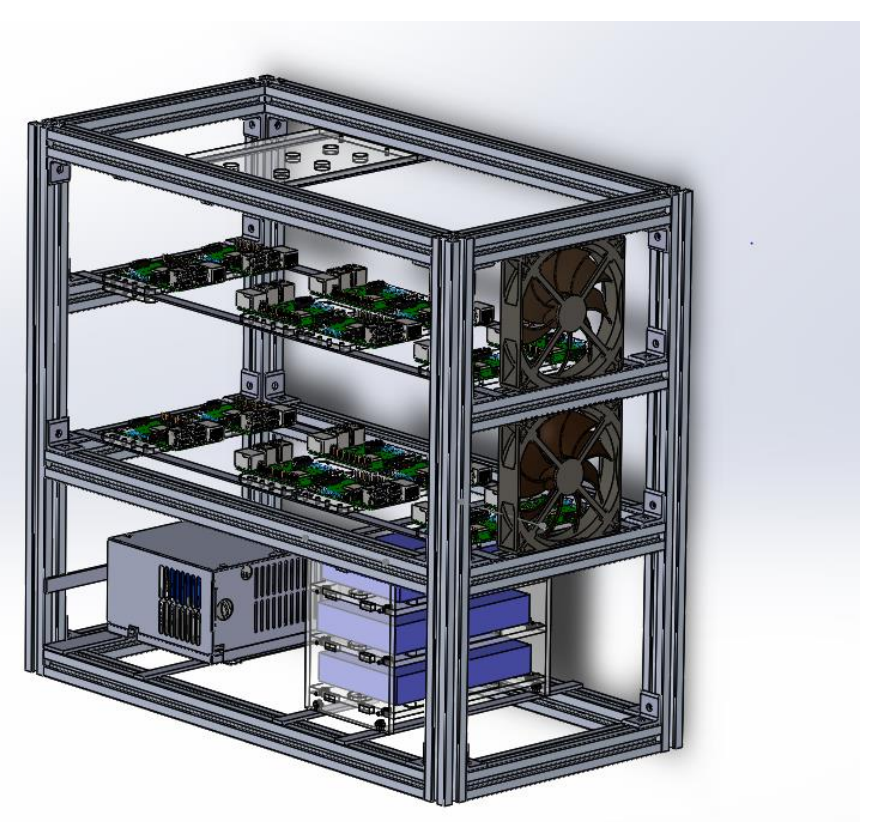

Figure 10: CAD model of the cluster

In order to distribute the workload across all the PIs, a new an architecture had to be developed to be able accept jobs from MATLAB, compute the results and send back. As it currently stands, MATLAB is not currently compatible to run standalone applications on a Raspberry PI. A workaround was to redevelop the code into Python that would be able to accept inputs fed from MATLAB, perform the calculations and output the results to a mat file that MATLAB can easily read. The information can be transferred across a high bandwidth network, to achieve the lowest latency. Figure 11 below represents the flow of information throughout the cluster computer. 


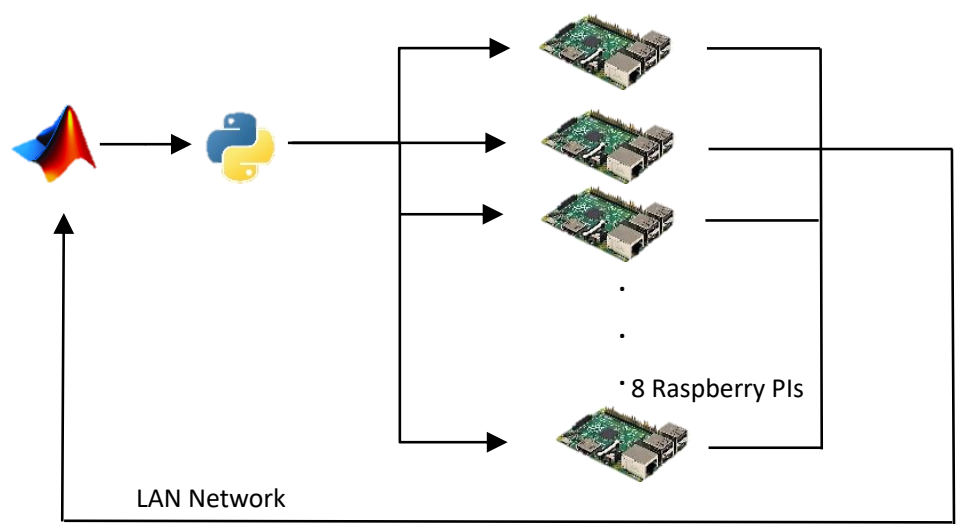

Figure 11: Flowchart representing the workflow through the cluster computer

This method to decrease computational time was successful, however, the analytical method of calculating the weight of the wing was scratched from this report and will be revised in future developments of this program. The cluster computer was still able to decrease the computational time by distributing jobs for calculating the fuel fraction method within the total iterative process.

\subsection{Verification and Validation}

Every computer program created must pass through the four main testing stages in order to be fully validated before its release. These testing stages are shown in Figure 12 below.

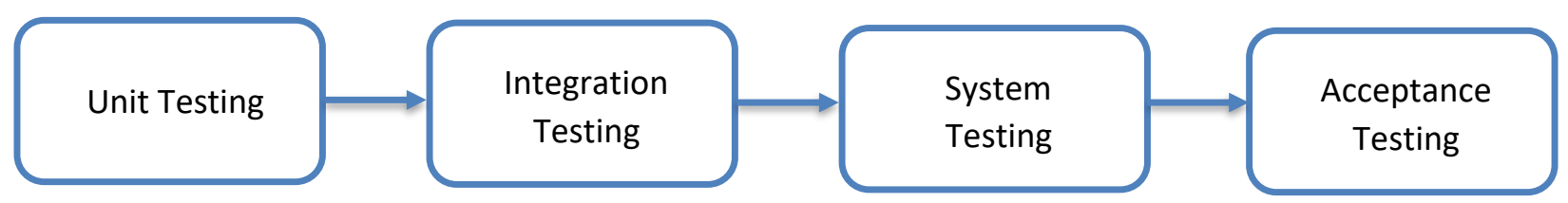

Figure 12: Four levels of software testing

Unit Testing represents the first stage, and this involves extensive testing of each component of the product. As an example, if one were to build a computer, each component such as the motherboard, power supply, optical drive etc. should be tested individually. The fuel fraction method, aerodynamic calculations, Raymers weight calculations, the calculation of the structural factor are all seen as individual units. The next testing stage, Integration Testing, involves the testing of how the different units work together. Using the computer building example, one would 
want to verify that the motherboard receives power from the power supply and the CPU and RAM are fully integrated with the motherboard. The fuel fraction method must produce a TOGW that the power required equation uses to determine the $W / P$ and the $s$ is calculated from the summation of the weight equations and so on. These previous two testing stages fall under term verification. The next stage, System Testing, involves using a team of independent testers, using multiple different testing schemes, to determine if the final product is producing results that fall under the requirements that were laid out by the developers. The testers would determine if the PC, one is building, can turn on, turn off, open the CMD prompt, execute commands etc. The developer for this computer program created specific requirements such as the program must be able to allow the user to input design constraints, the program should be able to calculate the lowest the most efficient aircraft, lowest TOGW that fall within these constraints and the program should output these results to readable text file for further analysis by the user. The last testing stage is the Acceptance Testing. This involves allowing the user to test the final product to determine if it is acceptable before distribution. These last two testing stages fall under validation. This computer program currently is in Integration Testing stage.

During the integration testing, one of the testing schemes was designed to determine the bounds of the user defined design constraints of this program. After analysis of the equations used, it was determined that these constraints have a coupled relationship. The user would not be able to change one constraint without it affecting another. The question is, what are the bounds of the constraints in this methodology? Dozens of the runs were conducted to roughly determine the limits of the user. Figure 13 and 14 below represents these results.

$$
\begin{gathered}
0<R<1000[\mathrm{nmi}] \\
0<E<15[\mathrm{hrs}] \\
50<V c<300[\mathrm{kts}] \\
200<W p<3000[\mathrm{lbs}]
\end{gathered}
$$

Figure 13: Limits of the design constraints from regression testing 


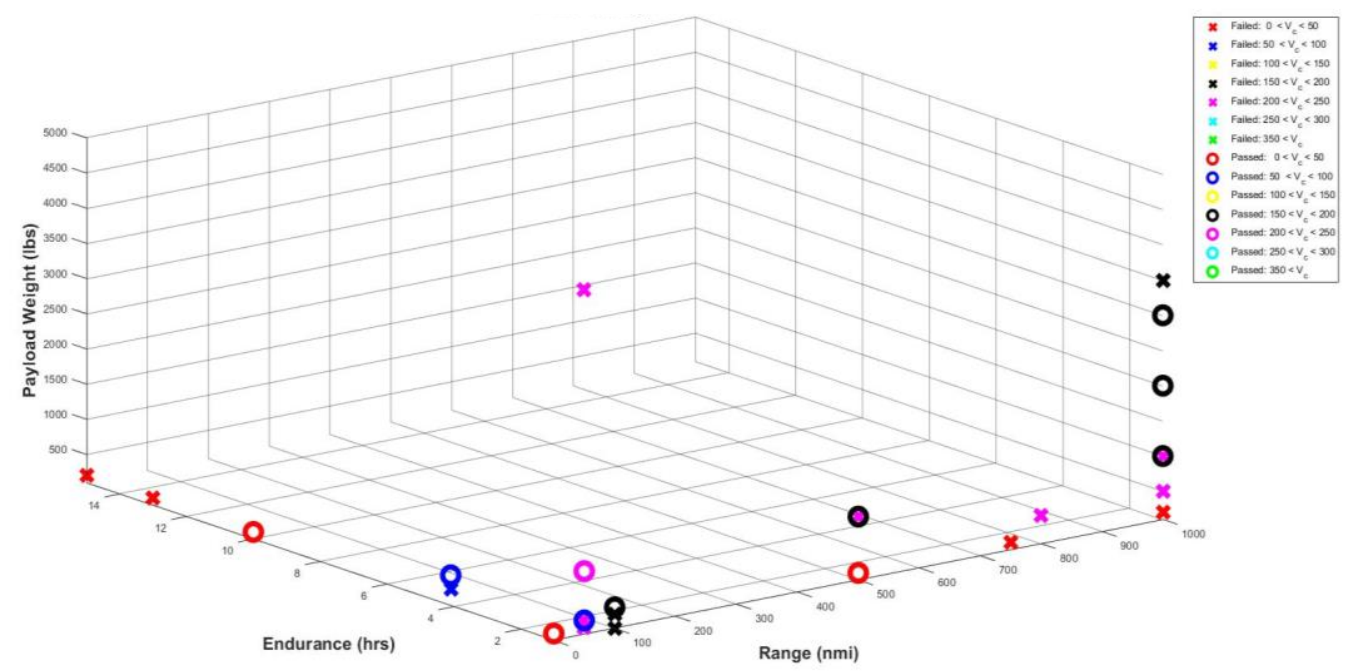

Figure 14: Boundary testing results of the user defined design constraints

\section{Results and Discussion}

Several aircraft design simulations were conducted in the testing of this program. Two of these simulations will be discussed in this section. The first run used a range of $650 \mathrm{nmi}$, endurance of $10 \mathrm{hrs}$, cruise velocity of $200 \mathrm{kts}$ and a payload weight of $2,000 \mathrm{lbs}$. A $3 \mathrm{~d}$ plot representing the iterative solution is shown in Figure 15 below.

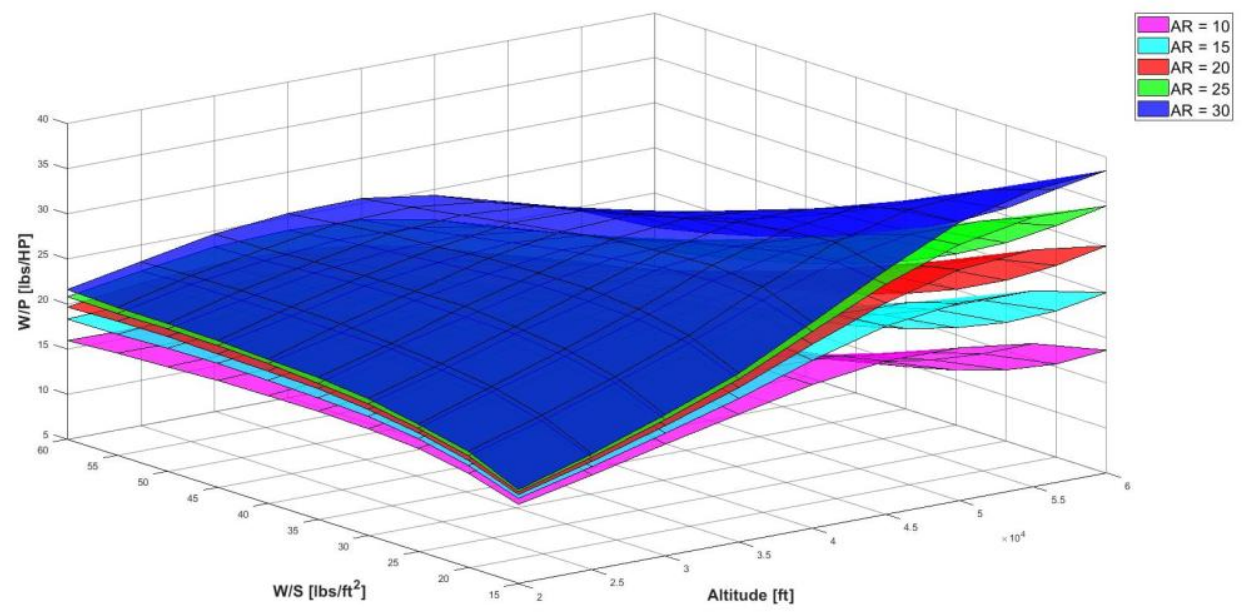

Figure 15: Variant results with design constraints of $R=650 \mathrm{nmi}, E=10 \mathrm{hrs}, V_{\text {crs }}=200 \mathrm{kts}, W_{\text {pay }}=2000 \mathrm{lbs}$ 
This plot represents the family of aircraft that were generated at various $A R, W / S$ and cruise altitudes. The $y$-axis represents the $W / P$ which is the TOGW over the power required. The TOGW constants and TO and LND constraints were then added and represented in Figure 16 below.
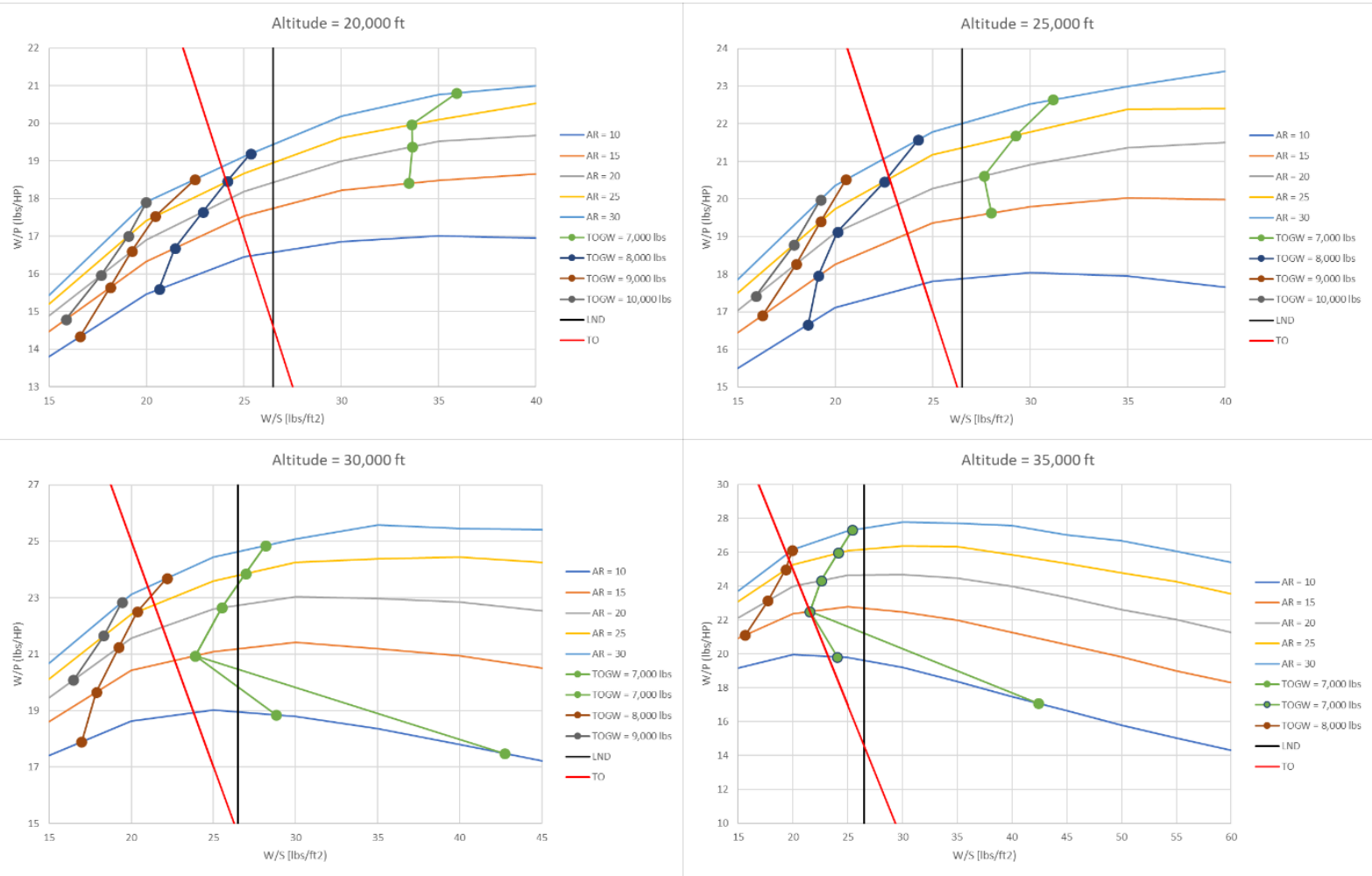

Figure 16: $T O G W$ constants for $R=650 \mathrm{nmi}, E=10 \mathrm{hrs}, V_{\text {crs }}=200 \mathrm{kts}, W_{\text {pay }}=2,000 \mathrm{lbs}$

The family of aircraft were split up into 2D plots for easier representation. At an altitude of 30,000ft and 35,000ft it is interesting to note the 8,000lb TOGW line splits into two directions when the $A R$ is 10 . This suggests at this $A R$, there are multiple designs with the same $T O G W$. These results also suggest that there are no aircraft designs that have a TOGW less than $8,000 \mathrm{lbs}$. There are no aircraft that were produced to the right of the least constant TOGW line, which means this is the least $T O G W$ one can achieve with these design constraints. To the left of this, the TOGW will only increase.

The landing and takeoff constraints must now be considered before choosing an aircraft. The landing constraint, represented by the vertical black line, represents the $W / S$ the aircraft must have in order to achieve a landing distance of 2,000ft. As the $W / S$ increases the takeoff distance 
will increase, so only an aircraft to the left of this line will be considered. The takeoff constraint, represented by the red line, represents the $W / S$ and $W / P$ the aircraft must have in order to takeoff at a distance of 3,000ft. As the W/S increases the takeoff distance will increase, so only aircraft that are to the left of this constraint can be considered. After considering these constraints, the efficient aircraft can be chosen at every cruising altitude. At an altitude of 35,000ft the most efficient design will be an $A R$ of $25, W / S$ of $20 \mathrm{lbs} / \mathrm{ft}^{2}$ with a $T O G W$ of around $9,000 \mathrm{lbs}$. The same method of choosing the efficient design can be applied to every cruising altitude. This methodology was applied to an altitude of up to 60,000ft, however, only MALE UAVS are considered in this report. If one wanted to design a HALE (high altitude long endurance) UAV the aircraft characteristics would have to be altered inside the program to reflect a comparative aircraft such as the MQ-4 Triton. The design constraints would also be changed to reflect a HALE UAV.

The second run that was conducted had a range of $250 \mathrm{nmi}$, endurance of $15 \mathrm{hrs}$, cruise velocity of $150 \mathrm{kts}$ and a payload of 3,000lbs. Figure 17 below represented the family of aircraft generated by the algorithm.

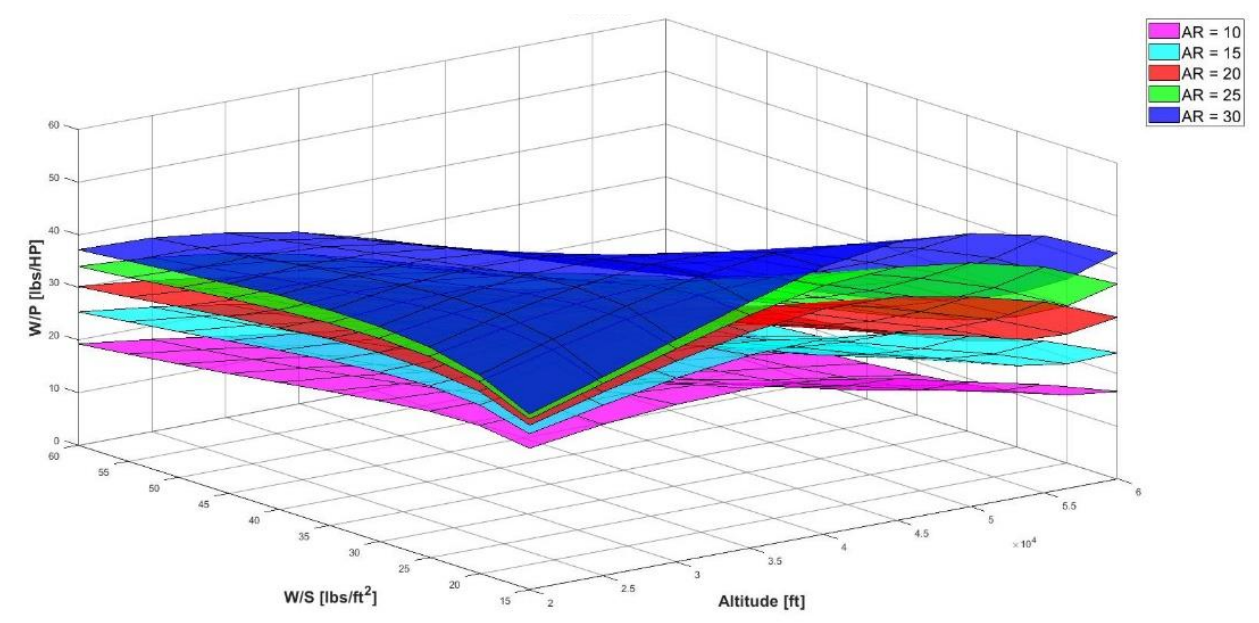

Figure 17: Variant results with design constraints of $R=250 \mathrm{nmi}, E=15 \mathrm{hrs}, \mathrm{V}_{\text {crs }}=150 \mathrm{kts}, \mathrm{W}_{\text {pay }}=3,000 \mathrm{lbs}$

The run that was conducted considered the same range of design variables as the previous run. Figure 18 below represent the same family of aircraft split up by cruising altitude with the same takeoff and landing constraints plotted. 

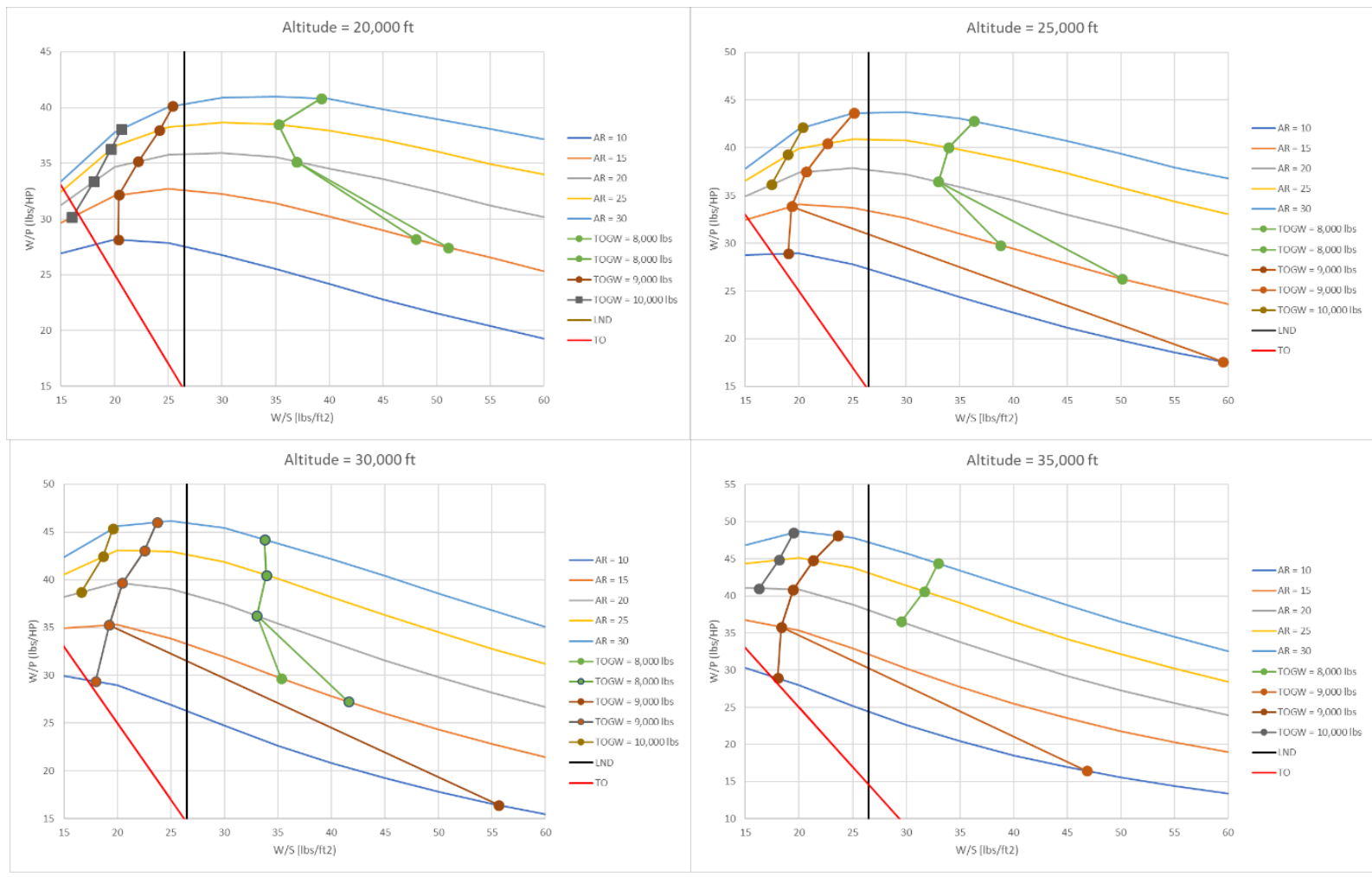

Figure 18: TOGW constants for $R=250 \mathrm{nmi}, E=15 \mathrm{hrs}, V_{\text {crs }}=150 \mathrm{kts}, W_{\text {pay }}=3,000 \mathrm{lbs}$

It is interesting to point out that there are no valid aircraft designs to choose from at altitudes from $25,000 \mathrm{ft}-35,000 \mathrm{ft}$. Unfortunately, currently, the computer program is not capable of detecting these instances and not capable of displaying a recommended design. The plotting of the constant TOGW, LND and TO constraints and choosing the design had to be done manually in Excel. However, future iterations of this program will be able to solve this data analytics issue. 


\section{Conclusion}

This report highlights the methods used to create an efficient conceptual design system capable of maximizing the efficiency of a MALE UAV. The conceptual design method, as described in this report, yields several families of aircraft with various configurations which all meet the design constraints imparted. These family of aircraft were then plotted individually on a graph along with lines of constant gross weight along with lines representing additional constraints such as takeoff and landing distance. From the final graphs, an efficient design configuration was determined by finding an aircraft which falls between all constraints, and this aircraft represents the most efficient design possible under the initial specifications from the beginning of the design.

As of today, this program contains the bedrock for efficient UAVs designs in the conceptual stage. Several improvements will be made and will be discussed in detail in the next section. The code is still considered static, in which it will crash if the constraints, set by the user, are unacceptable. This was established through the limit testing stage. Again, this does not mean an aircraft cannot be created with given these constraints, it means that the somewhere in the iteration process, the calculated design variables would not allow the termination criteria to be satisfied and caused a crash. This would have to be addressed in future developments. Lastly this program needs to complete the final testing stages and receive validation before being released to potential users. 


\section{Future Work}

As it stands, this program should be seen as a foundation that has plenty of room to expand. The code methodology can be refined to become more efficient with the increased integration of the cluster computer. The current computing power from the is not being utilized to its fullest. Parallel algorithms can be implemented inside the current program that can dispatch jobs to the computer using a more advanced architectural design. Additionally, more cores can be added to the computer with an additional purchase of eight Raspberry PIs. Currently the casing of the computer was designed to hold sixteen PIs and currently only eight are installed.

The methodology itself also has room to expand. The code currently contains a database of engines that the algorithm will select from to meet the power install requirement and have the lowest dry weight. The database only contains turbocharged engines which can severely limit the ability to have high cruising altitude. An addition of supercharged engines along with diesel grade turbocharged and supercharges engines will further expand the algorithms capability to design a high-altitude aircraft. Additionally, this is a static program. It lacks dynamic capability such as recognizing dead designs. As the program iterates through and designs the family of aircraft, if it comes across a specific $A R$, cruise altitude and $W / S$ that will not produce a valid structural factor and/or $L / D_{c r s}$, the program will terminate. The algorithm can be modified to recognize this as a dead aircraft and move onto the next iteration.

Machine learning can also be introduced into the algorithm to guide the user into making appropriate choices for the design constraints that are within the bounds of the algorithm. It was discussed in the Results and Discussion section that the current algorithm places limits on what the user can chose as the design constraints. The limits that were defined are based off only a handful of tests. Machine learning code can be integrated into the current algorithm to further refine these limits by running numerous design simulations.

Currently this algorithm is restricted to only the conceptual design phase. An expansion into the preliminary design phase will allow the user to determine if the most efficient design is feasible.

A full validation process is needed to determine is this methodology can produce accurate results. This will involve the process of redesigning an already proven aircraft such as the MQ-9 and MQ-1 and determining if the design variables produced from the program come within a certain tolerance of the actual design variables of these aircraft. Additionally, a test team will have 
to preform regression testing on this product to determine if program is behaving as outlined in the methodology. 


\section{References}

1. “A Brief History of Aircraft Structures,” Aerospace Engineering Blog, 24-Jul-2018. [Online]. Available: https://aerospaceengineeringblog.com/aircraft-structures/. [Accessed: 02-Nov-2019].

2. “Cluster Computing: History, Applications and Benefits," UKEssays.com. [Online]. Available: https://www.ukessays.com/essays/computer-science/cluster-computinghistory-applications-9597.php. [Accessed: 02-Nov-2019].

3. “Continental 500 Series AvGas Engine," Continental Aerospace Technologies. [Online]. Available: https://www.continentalmotors.aero/engines/500.aspx. [Accessed: 27-Oct2018].

4. T. C. Corke, Design of aircraft. Singapore: Pearson Education, 2005.

5. "Cray Supercomputers Play Key Role in Designing Boeing 787 Dreamliner." Cray Inc. Accessed September 30, 2019. https://investors.cray.com/news-releases/news-releasedetails/cray-supercomputers-play-key-role-designing-boeing-787.

6. Y. Domun, "Aircraft Design Process Overview," EngineeringClicks, 06-Oct-2018. [Online]. Available: https://www.engineeringclicks.com/aircraft-design-process/. [Accessed: 20-Aug-2019].

7. B. Dunbar, "NASA Dryden Fact Sheet - ALTUS II," NASA, 31-Mar-2015. [Online]. Available: https://www.nasa.gov/centers/armstrong/news/FactSheets/FS-058DFRC.html. [Accessed: 20-2019].

8. Peter Gall, Class Lecture, Benjamin Statler College of Engineering and Mineral Resources, West Virginia University, Morgantown, W.V., Fall 2014.

9. L. George, “3D Transistor Intel Reinvents Transistors," electroSome, 13-Nov-2014. [Online]. Available: https://electrosome.com/3d-transistor/. [Accessed: 02-Nov-2019].

10. J. Gundlach, "Multi-Disciplinary Design Optimization of Subsonic Fixed-Wing Unmanned Aerial Vehicles Projected Through 202," dissertation, 2004.

11. "MQ-1B Predator," U.S. Air Force, 23-Sep-2015. [Online]. Available: https://www.af.mil/About-Us/Fact-Sheets/Display/Article/104469/mq-1b-predator/. [Accessed: 02-Aug-2019].

12. “MQ-9 Reaper," U.S. Air Force, 23-Sep-2015. [Online]. Available: https://www.af.mil/About-Us/Fact-Sheets/Display/Article/104470/mq-9-reaper/. [Accessed: 02-Jul-2018]. 
13. D. P. Raymer, Aircraft Design: a conceptual approach. Washington, D.C., 1992.

14. "RQ-4 Global Hawk," U.S. Air Force, 27-Oct-2014. [Online]. Available: https://www.af.mil/About-Us/Fact-Sheets/Display/Article/104516/rq-4-global-hawk/. [Accessed: 15-Aug-2019].

15. T. Scheve, "How the MQ-9 Reaper Works," HowStuffWorks Science, 25-Jul-2019. [Online]. Available: https://science.howstuffworks.com/reaper1.htm. [Accessed: 28-Oct2019].

16. "Supercomputer redesign of aeroplane wing mirrors bird anatomy," Nature News.

[Online]. Available: https://www.nature.com/news/supercomputer-redesign-of-aeroplanewing-mirrors-bird-anatomy-1.22759. [Accessed: 02-Nov-2019].

17. The Editors of Encyclopaedia Britannica, "Moore's law," Encyclopaedia Britannica, 29Mar-2019. [Online]. Available: https://www.britannica.com/technology/Moores-law. [Accessed: 20-May-2019].

18. WagnerOct, "Watch a supercomputer design a radical new wing for airplanes," Science, 27-Dec-2018. [Online]. Available: https://www.sciencemag.org/news/2017/10/watchsupercomputer-design-radical-new-wing-airplanes. [Accessed: 02-Nov-2019].

19. B. Yirka, "A supercomputer tool that can optimize airplane wing design offers improved detail," Tech Xplore - Technology and Engineering news, 05-Oct-2017. [Online]. Available: https://techxplore.com/news/2017-10-supercomputer-tool-optimize-airplanewing.html. [Accessed: 02-Oct-2019]. 


\section{Appendix A}

Appendix A represents the CAD models that were developed to gather further characteristics for the comparative aircraft study. 


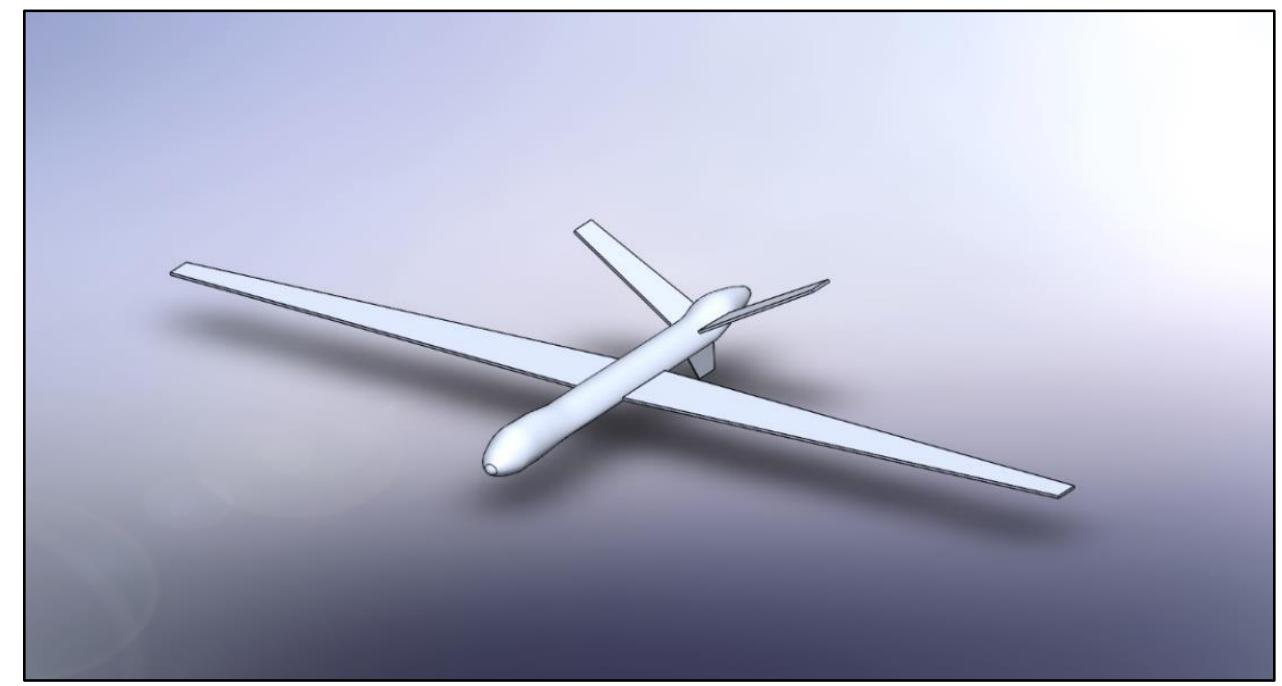

Figure 19: MQ-9 developed in CAD

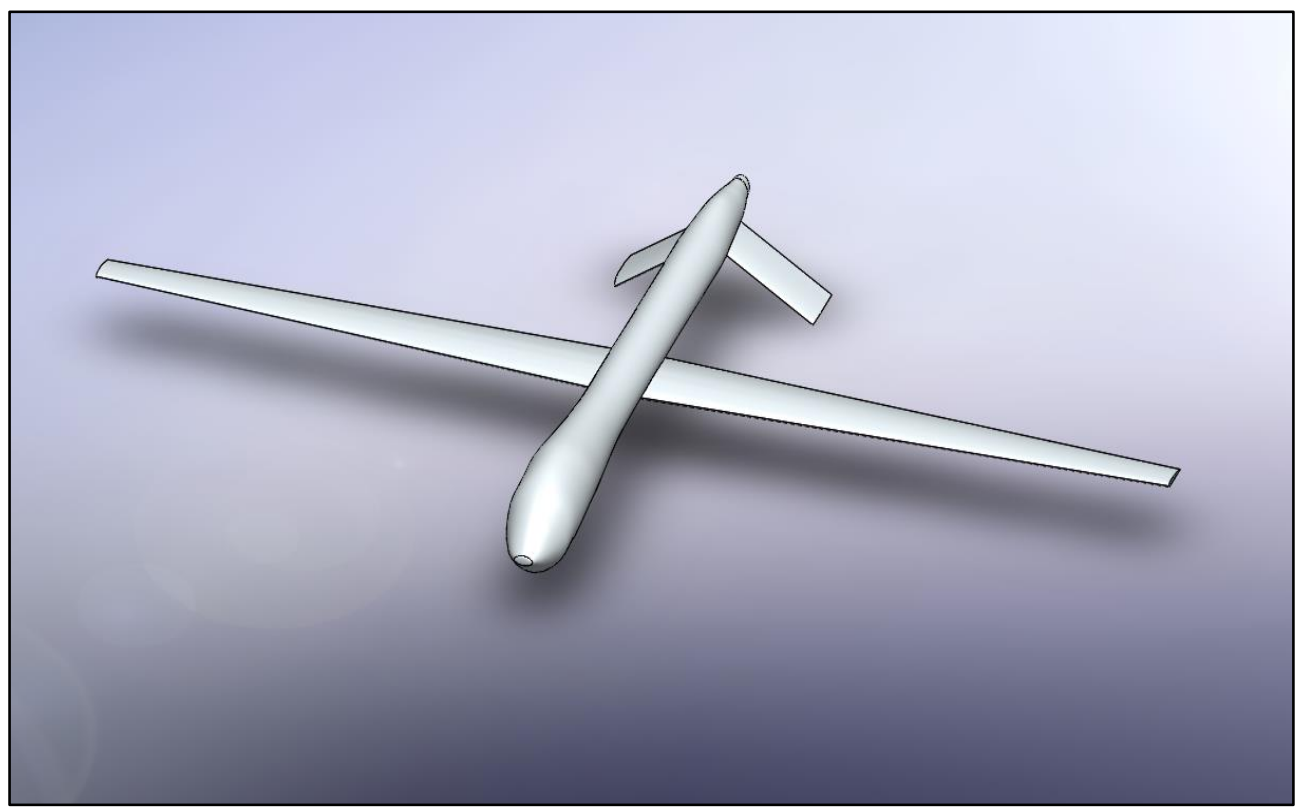

Figure 20: MQ-1 developed in CAD 


\section{Appendix B}

Appendix B represents GUIs created to ease the use of the computer program. 


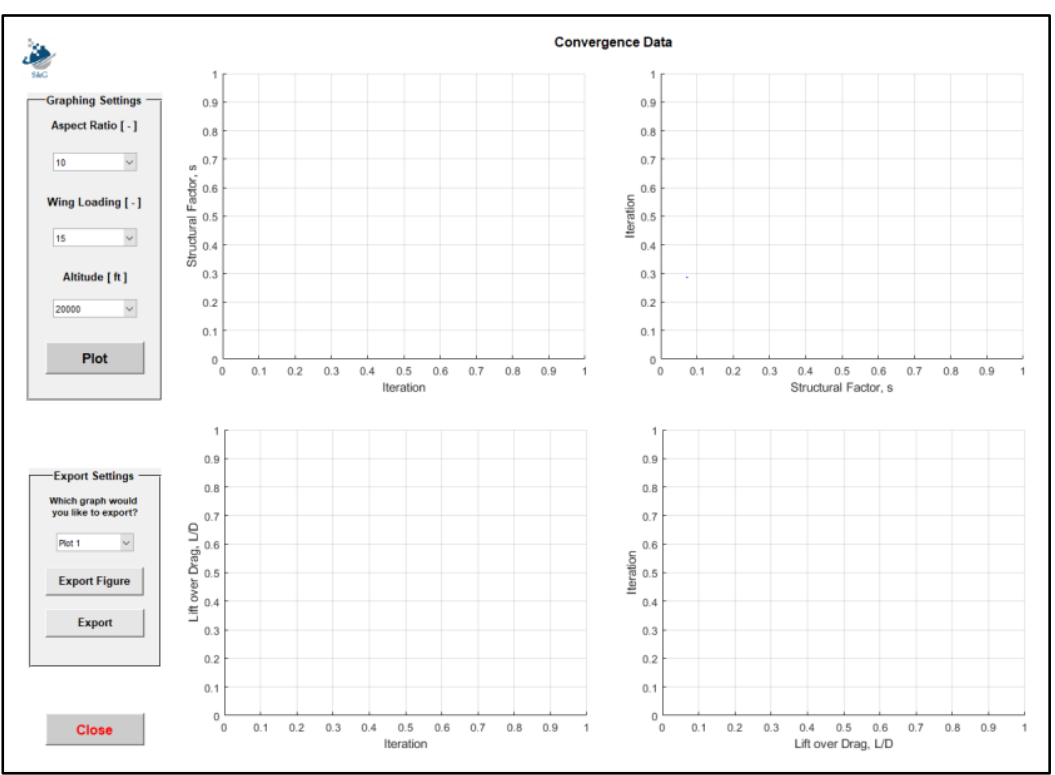

Figure 21: Convergence Data GUI

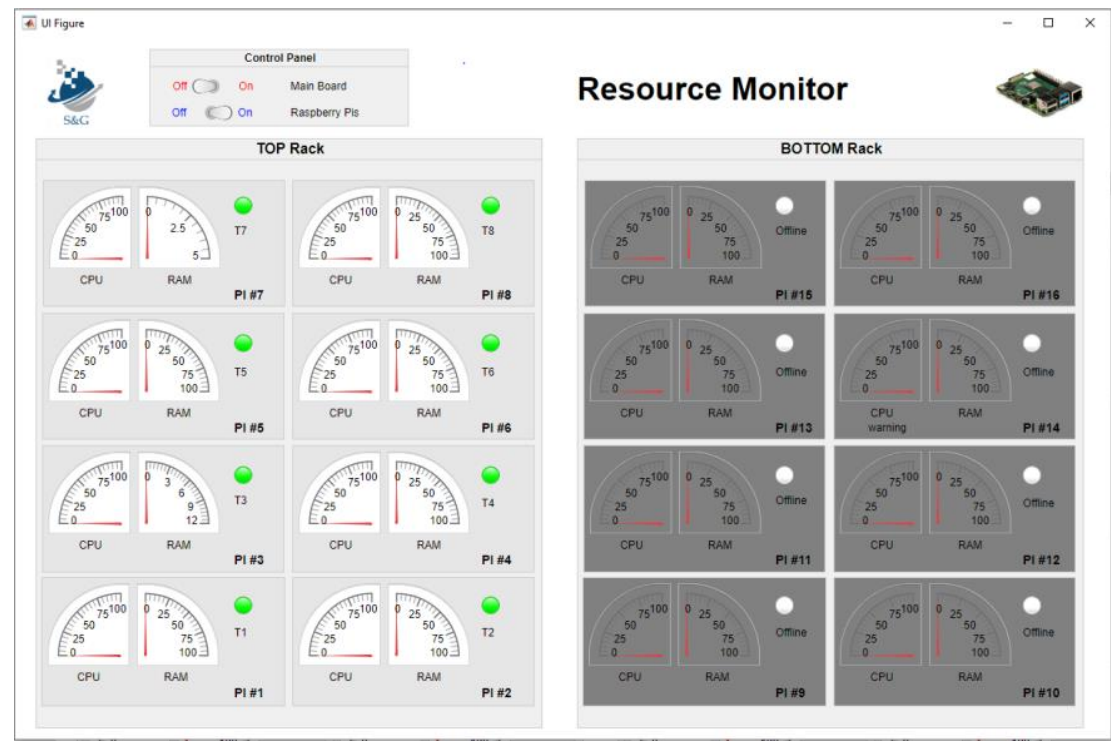

Figure 22: Resource Center GUI 


\section{Appendix C}

Appendix $\mathrm{C}$ represents the Excel sheets that aided in the calculations as seen in this report. It was cleaner to represent these tables in a $C D$ that is available with the author's permission. 